\title{
PATHOGENESIS AND PATHOLOGY OF HEMATOGENOUS INFECTIONS OF THE FETUS AND NEWBORN
}

\author{
Achiléa Lisboa Bittencourt $\square$ Department of Pathology, Federal University of Bahia, \\ Brazil
}

\author{
Aparecida Gomes Pinto Garcia $\square$ Laboratory of Pathology, Instituto Fernandes Frgueira, \\ Oswaldo Cruz Foundation, Rio de faneiro, Brazil (in memoriam)
}

The earlier infections occur in intrauterine life the more severe are they. When the infection develops during embryogenesis, the lesions are much more serious, sometimes causing disruptions (malformations). At this time the organs are not completely formed and microorganisms may interfere with organogenesis to such an extent that the development of the functions necessary for viability become impaired.

Infection acquired in utero may tesult in resorption of the embryo, abortion, stillbirth, neonatal death, intrauterine growth retardation (IUGR), or prematurity. The infected newborns commonly are apparentily normal at birth but they may develop a late onset disease. Otherwise, neonates presenting symptomatology may develop untoward sequelae.

As many fetuses die some time before birth, maceration is a frequent finding in stillborn autopsies (Figure 1). The macerated fetuses must be submitted to a complete autopsy with microscopic examination of the more preserved organs. Inflammatory cells (Figure 2A), viral inclusions and foci of calcification may be visualized in most organs, even in fetuses with marked degrees of maceration. Less frequently, it is possible to detect the etiologic agent (Figure 2B) or the viral inclusions.

Even though many pathologic features are similar in congenital infections caused by different agents, there are important differences in pathogenesis and pathology:

\section{VIRAL INFECTIONS}

Viruses consist of a core of either RNA or DNA, and they are protected by a protein coat or capsid, possessing in some instances an outer envelope, a lipid bilaminar membrane, derived from host cells. The nucleocapsid is the packaged form of the viral genome. The virus particles transfer nucleic acids from one cell to another. To survive, viruses must gain access to the interior of the host cell because they

Address correspondence to Achiléa L. Bittencourt, MD, Hospital Prof. Edgard Santos, Serviço de Anatomia Patológica, Rua Augusto Viana s/n - Canela CEP: 40110-160 Salvador-Bahia-Brasil. E-mail: achilea@
uol.com.br 


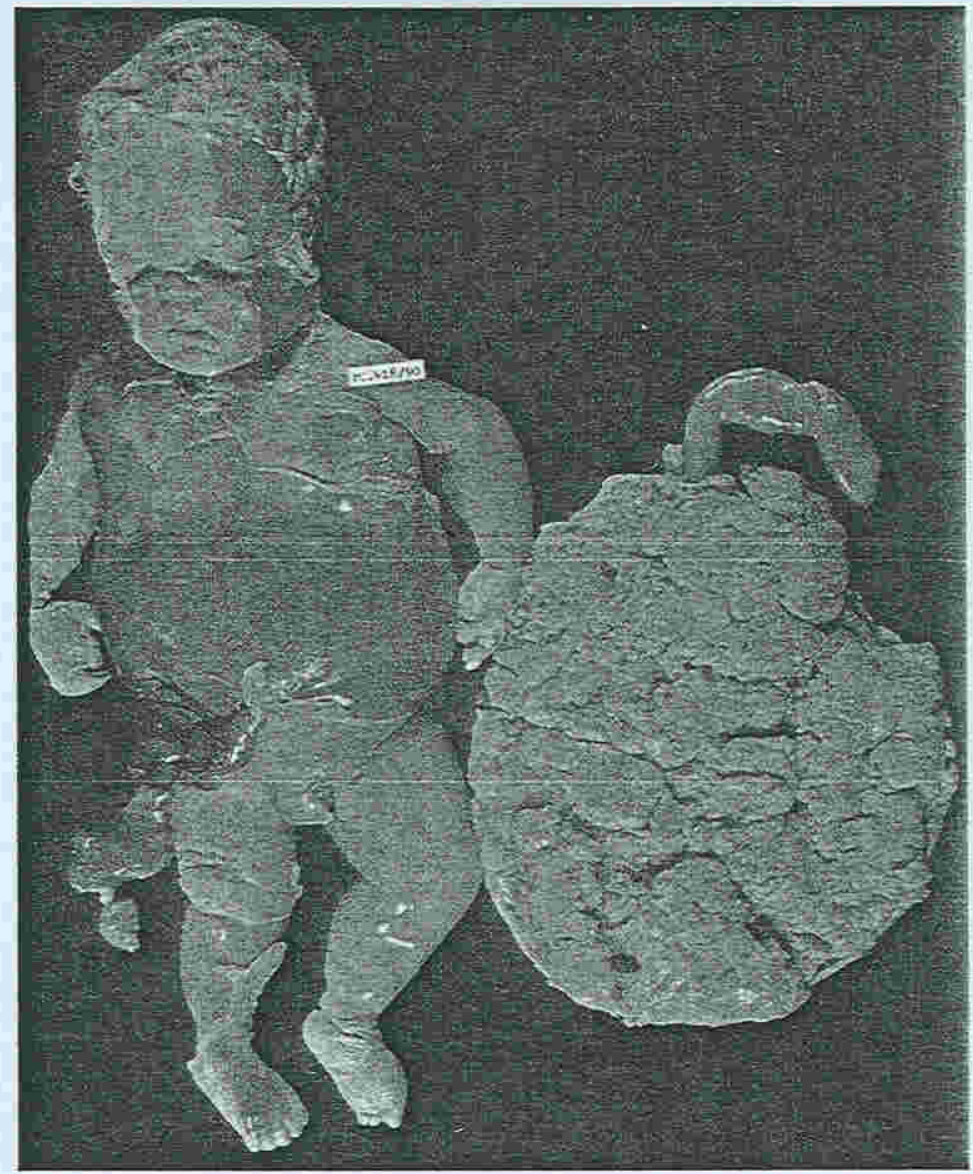

FIGURE 1. Congenital syphilis. A hidropic fetus with marked maceration.

require many of the host cell's biosynthetic processes for replication. The virion is a complete virus particle.

Viral infection of a cell can lead to any of several possible outcomes:

1. Nonproductive infection can develop with blockage of viral replication and the viral genome may be lost from the cell.

2. Viral genetic information may become integrated as DNA in the cellular genome or may persist as episomal DNA in these surviving cells.

3. Virus may become dormant with little viral gene expression resulting in a latent infection.

4. Productive viral infection may result in cell death.

5. Infected cell may survive and continue to produce viruses at a low level, resulting in a chronic infection [1]. 


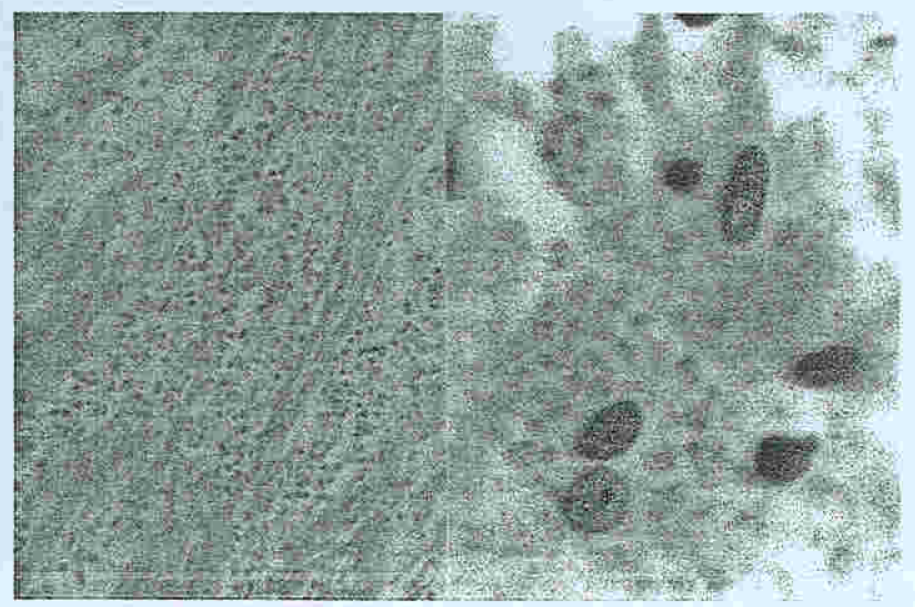

FIGURE 2. Congenital Chagas' disease. Tissues from a fetus with marked maceration. (A) Skeletal muscle presenting mononuclear cells dissociating the fibers (H\&E, x400). (B) Presence of parasitized microglial cells in the brain $(H \& E, \times 1200)$.

One way of detecting virus replication in cells is to observe changes in cell structure or the viral cytopathic effect. Four of the most common effects of viral infection are cell rounding and detachment of the structures, cell death, syncytium formation, and inclusion body formation. The virus can induce cell death by two mechanisms: necrosis and apoptosis (programmed cell death). During necrosis there is swelling of the cell, disruption of organized structures, and lysis. During apoptosis, there is DNA condensation and fragmentation, and cell shrinkage. The inclusion bodies or factories are formed in the site of viral replication in the nucleus or in the cytoplasm. They result from the accumulation of virions and other products of viral replication. These structures help the pathologist in the recognition of a viral infection [1].

Viral dissemination in the fetus may occur through the bloodstream or within nerves and the two processes are not mutually exclusive. Certain viruses present both types of dissemination, such as the varicella-zoster virus. When the virus reaches the fetal circulation it can travel either free or within lymphocytes or cells of the monocyte-macrophage lineage. The vascular endothelial cells are susceptible to viral infection and they may be responsible for the maintenance of viremia [2].

Acute viral infections of the central nervous system (CNS) are an important cause of fetal morbidity. Many pathways of viral spread to the CNS may occur. No free passage of the virus through the capillary wall of the cerebral microvasculature is possible because the capillary endothelial cells have tight junctions with an underlying dense basement membrane. Viruses can spread from the bloodstream to the CNS through fenestrated choroid plexus microvascular endothelial cells to enter the stroma of the choroid plexus. They can infect the choroid plexus epithelial cells that have direct contact with the cerebrospinal fluid. The infected cerebrospinal fluid may contaminate the ependymal cells lining the ventricles and, subsequently, 
the adjacent brain tissue. Another pathway of viral spread to the CNS is through a primary infection of the endothelial cells of the cerebral vessels. Diapedesis of virally infected leucocytes may provide another mechanism by which viruses can cross the endothelial cell [2].

\section{CONGENITAL RUBELLA}

Rubella is caused by an RNA virus of the Rubivirus genus (family Togoviridae). The virus causes either a benign exanthem occurring predominantly in children, or a transplacentally acquired infection. The frequency of fetal involvement in congenital rubella depends on the time of maternal infection. During the first two months of gestation the majority of the products of conception are infected. The rate of fetal infection falls after the llth week of gestation to reach a low of 25 to $33 \%$ during the second trimester; it raises again near term [3].

Sequelae are seen in 67 to $85 \%$ of neonates infected in the first trimester [3]. The disease is more severe and disseminated, and disruptions or reaborption of the embryo may occur during the first 2 months of pregnancy. The fetus may be spared in cases of placental infection. The protection given by the placenta against infection is highlighted by the fact that only one identical twin may be infected. It has been postulated that dissemination of the rubella virus to the fetus occurs through embolization of virus infected chorionic endothelial cells. Nonetheless, the virus also can be transported inside blood cells [4].

The early lesions of congenital rubella are caused by cytolysis, inhibition of cell growth, and interference of the blood supply due to widespread vasculitis. However, the most important pathogenic mechanism is related to the interference of the blood supply. The vascular lesions are severe and disseminated, and they have been implicated in the genesis of the anomalies observed in congenital rubella. Researchers assume that the cytopathic effect of rubella virus is not as important as those observed in other viral infections. This is supported by the observations that the virus presents a low destructive potential or no cytopathic effect for cells growing in vitro [4].

The precise mechanism of rubella viral teratogenesis remains unknown but is likely to be multifactorial. Among favored hypotheses is that the direct effect of virus replication on clones of embryonic cells and their progeny during critical stages of ontogeny of specific fetal organs gives rise to the wide range of abnormalities that together comprise the congenital rubella syndrome [3]. Some studies have shown that chronically infected cells present chromosomal breaks, reduced cellular multiplication time, and increased production of a protein inhibitor that causes mitotic arrest in some cell types. Also, rubella virus interferes with mitosis through an adverse effect on actin microfilament and, also interferes with the cell receptors to specific growth factors. Slowing of the mitotic rate along with death of some cells during organogenesis might help explain, at least in part, the pathogenesis of congenital defects and of the cell number reduction observed in infected fetuses [4]. 
A number of mechanisms such as persistence of viral infection, virus reactivation, immunological abnormalities, and vascular insuficiency are considered to be implicated in the genesis of the late onset lesions of congenital rubella. The hallmark of rubella infection is its chronicity with the tendency for virus to persist throughout fetal and postnatal life. More than $80 \%$ of newborns eliminate a great quantity of virus through nasopharyngeal secretions and urine, and $3 \%$ present persistent viral elimination up to 20 months of age. This persistence explains the progressive and protracted course of this infection [3]. The progressive and fatal panencephalitis that occurs during the second decade of life is considered to be the result of rubella virus reactivation after many years of latency. Immunologic abnormalities result from the persistent presence of immune complexes and autoantibodies [4]. Autoimmune mechanisms may cause hyperthyroidism, hypothyroidism, or thyroiditis in $5 \%$ of patients congenitally infected. Hypertension and retinopathy are example of rubella complications due to vascular changes. Certain HLA types and other genetic factors also have been considered in the pathogenesis of postnatal complications of rubella [4].

\section{Pathology}

Abortuses and stillborns show at autopsy generalized involvement frequently associated with organ hypoplasia. However, hepatosplenomegaly can be observed [4]. Thickening of the intima of the aorta and other large elastic arteries has been reported. Disruptions are observed in cases of early gestational infections [5]. In the study of 44 autopsies of congenital rubella, Garcia and Lana found the following frequency of malformations: cardiovascular $72 \%$ (Figure 3), digestive $25 \%$, external $25 \%$, urinary $18 \%$, respiratory $11 \%$, and of the CNS $9 \%$

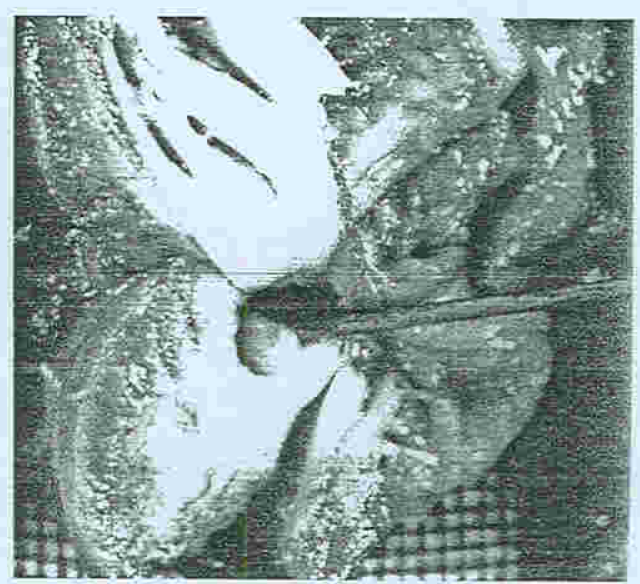

FIGURE 3. Congenital rubella. Heart with ventricular septal defect. Presence of a fibrotic nodule partially obliterating the defect. 


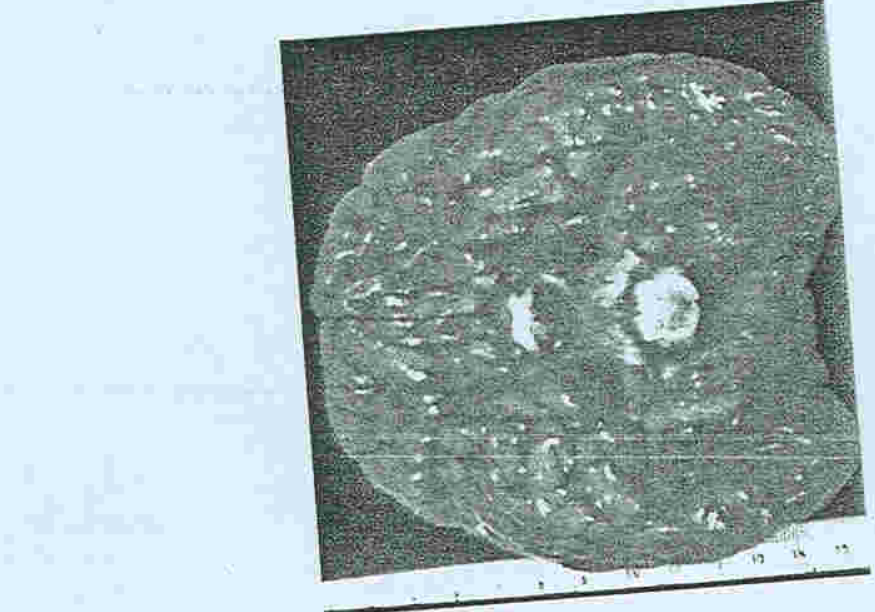

FIGURE 4. Congenital rubella. Agenesis of the cerebellar vermix.

(Figure 4) [6]. Cardiovascular and digestive anomalies found in this study are listed in Tables 1 and 2.

In contradistinction to other viral infections, cellular necrosis and secondary inflammation are rarely marked in congenital rubella, although a generalized vasculopathy predominates. Sometimes the lytic lesions vessels constitutes the most injured cells. Necrotizing angiopathy of small blar necrosis and secondary inflamcharacteristic pattern of early lesions. mation are observed less commonocytes. Both polymorphonuclear leucocytes and tion consists mainly of lymphoch As the lesions are progressive, both fibrotic and plasma cells are generally lacking found [4]. Intimal fibromuscular proliferation active inflammatory lesions are found [1]. Intmat fibrom

TABLE 1. Cardiac Malformations in Congenital Rubella [6]

Patent ductus arteriosus

associated with ventricular septal defect, atrial septal defect, or aortic coarctation

Tetralogy of Fallot

Vascular malformations (persistence of the left anomalies of the left subclavian artery, and the renal artery)

Hypoplasic left heart

Ventricular septal defect

Truncus arteriosus

Transposition of the great vessels

Endocardial cushion defect

Total 
TABLE 2. Malformations of the Gastrintestinal Tract in Congenital Rubella [6]

\begin{tabular}{lr}
\hline Isolated defects & 2 \\
Tracheoesophageal fistula & 2 \\
Duodenal atresia & 2 \\
Imperforate anus & 1 \\
Persistent cloaca & 1 \\
Malrotation of the small bowel & 1 \\
Multiple defects & 1 \\
Rectourethral fistula and imperforate anus & 1 \\
Duodenal atresia and imperforate anus & 11 \\
Ectopic anus and malrotation of the intestines & 1 \\
Total &
\end{tabular}

(Figure 5) is the main vascular lesion seen after the acute stage of the disease. More commonly, the vascular lesions are devoid of inflammation and calcification. They involve both the pulmonary and systemic systems, occurring predominantly in the aorta and pulmonary and major branch arteries such as the coronary, renal, and iliac vessels. Smaller muscular arteries also may be involved though less frequently. Changes in the media and internal elastica are rare [7]. Arterial stenosis may play an important role in the pathogenesis of the congenital rubella syndrome. Hypertension from narrowing of the renal arteries and infarcts with myocardial fibrosis results from coronary artery stenosis $[6,7]$. Nodular thickening and distortion of the heart valves also may be observed in congenital rubella [7]. Other lesions described in congenital rubella include pneumonitis and myocarditis [5].

The CNS lesions are very important because the most severe sequelae of congenital rubella are mental retardation and sensory and motor deficits. Chronic

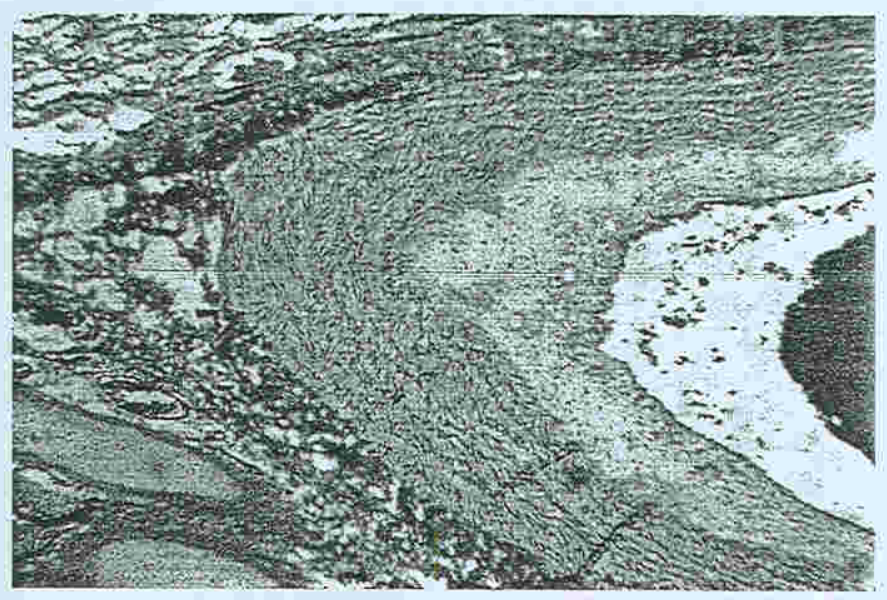

FIGURE 5. Congenital rubella. Branch of the pulmonary artery showing intimal thickening and reduction of the lumen $(H \& E, \times 125)$. 
lymphohistiocytic meningitis and encephalitis can be observed. Encephalitis is characterized by foci of glial proliferation along with perivascular lymphocytic infiltration. Necrosis and mineral deposits in capillary walls and in pericapillary tissues may be seen. The lesions occur particularly in the basal ganglia and midbrain and less frequently in the cerebral cortex [5].

Hypoplasia of the thymus and of the thymus-dependent lymphoid tissues are frequent findings in fetal autopsies. The thymus has small lobules separated by fibrous septa, severe lymphoid depletion, and lack of differentiation into cortex and medulla. Hassall's corpuscles are absent, cystic, or calcified (Figure 6) [8]. The spleen may present depleted lymphoid tissue and extramedullary hematopoiesis [5]. The characteristic macular dark red skin lesions that led to the designation blueberry muffin baby consist of dermal erythropoietic cell clusters [4].

Besides hematopoiesis, hepatocyte swelling, cholestasis, portal phlebitis, proliferation of biliary ducts, and giant cell transformation of hepatocytes have been described in the liver. Periportal fibrosis is a late manifestation of infection. Bone lesions occur in the epiphyseal and metaphyseal growth zones. The ingrowth of capillaries into the maturing cartilage columns is irregular and incomplete resulting in abnormal osteoid trabeculae with deficient mineralization [5].

Cataract is a common finding in congenital rubella. Through reverse transcription polimerase chain reaction (RT-PCR) Bosma et al. detected rubella virus RNA in formalin-fixed or cryopreserved lens aspirates obtained from congenitally infected children [9]. Cataractous lenses are spherical and pyknotic nuclei can be found in the lens nucleus. Other ocular microscopic changes are iritis, pigmentary degeneration in the ciliary body, and degeneration of retinal ganglion cells.

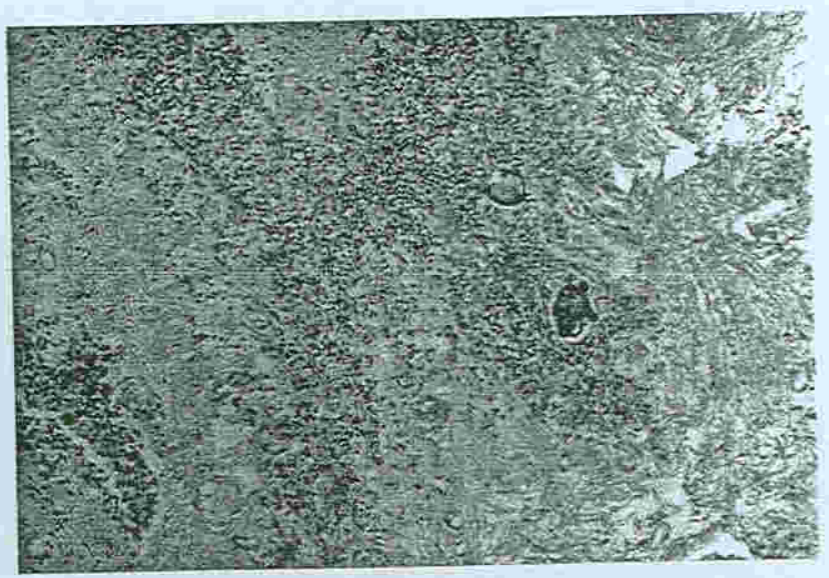

FIGURE 6. Congenital rubella. Atrophy of the thymus lobules, depletion of lymphocytes, absence of Hassall corpuscles, and presence of foci of calcification ( $H \& E, \times 40$ ). 
Neovascularization of the retina, glaucoma, and fibrosis of the conjuntiva may develop later. Microphthalmia also can be observed $[5,10]$.

The diagnosis is generally made taking into account the history of recent maternal infection, the serologic reactions, and the pathologic observations in the autopsy. Confirmation can be achieved by isolation of the rubella virus from placental or fetal tissues or by RT-PCR using formalin-fixed paraffin embedded fetal tissues $[4,9]$.

\section{CYTOMEGALOVIRUS}

Cytomegalovirus is a member of the family Herpesviridae, that also includes herpes simplex types 1 and 2, varicella-zoster virus (VZV), Epstein-Barr virus (EBV), and human herpesvirus 6 (HHV-6). A characteristic common to all herpesviruses is their ability to establish latency.

Intrauterine transmission of CMV infection occurs in 30 to $40 \%$ of pregnant women with primary infection. However, it may also result from maternal reinfection [11]. Infection by CMV acquired in utero may be asymptomatic. Fewer than $5 \%$ of congenitally infected infants develop symptoms during the newborn period. Cellular functions does not seem to be significantly impaired after viral penetration. The infected cells may retain viability despite continuous viral shedding: Adequate control of infection requires intact host immune response. Many immunologic mechanisms are involved in the pathogenesis of CMV infection [12]. As a consequence of persistent viral replication, a prolonged humoral response results in the formation of immune complexes that may be deposited in the renal glomeruli resulting in glomerulonephritis. Another indirect mechanism of cellular damage consists of lysis of infected cells by a cell-immune-mediated-reaction [11].

\section{Pathology}

The lesions in CMV infections are caused by the viral cytopathic effect or by vascular lesions [12]. The inflammation is associated with necrosis that leads to marked dysfunction of the involved structures [11]. The inflammatory infiltrate consists of lymphocytes, plasma cells, and macrophages. Cytomegalic cells with inclusions frequently are seen in recent lesions. The typical cytomegalic cell is swollen, with an enlarged nucleus distended by a huge inclusion that is separated from the nuclear membrane by a nonstaining halo (owl's eye). Inclusions also may be seen inside the cy toplasm as small, round, PAS-positive structures. They are argyrophilic with the Gomori's methanamine silver stain [12].

Disseminated disease can occur in the infected fetus but may sometimes involve only the CNS. Thickening and loss of transparency of the leptomeninges and extensive areas of parenchymal destruction are seen in the CNS (Figure 7). The following abnormalities may occur as sequelae: microcephaly, cerebral 


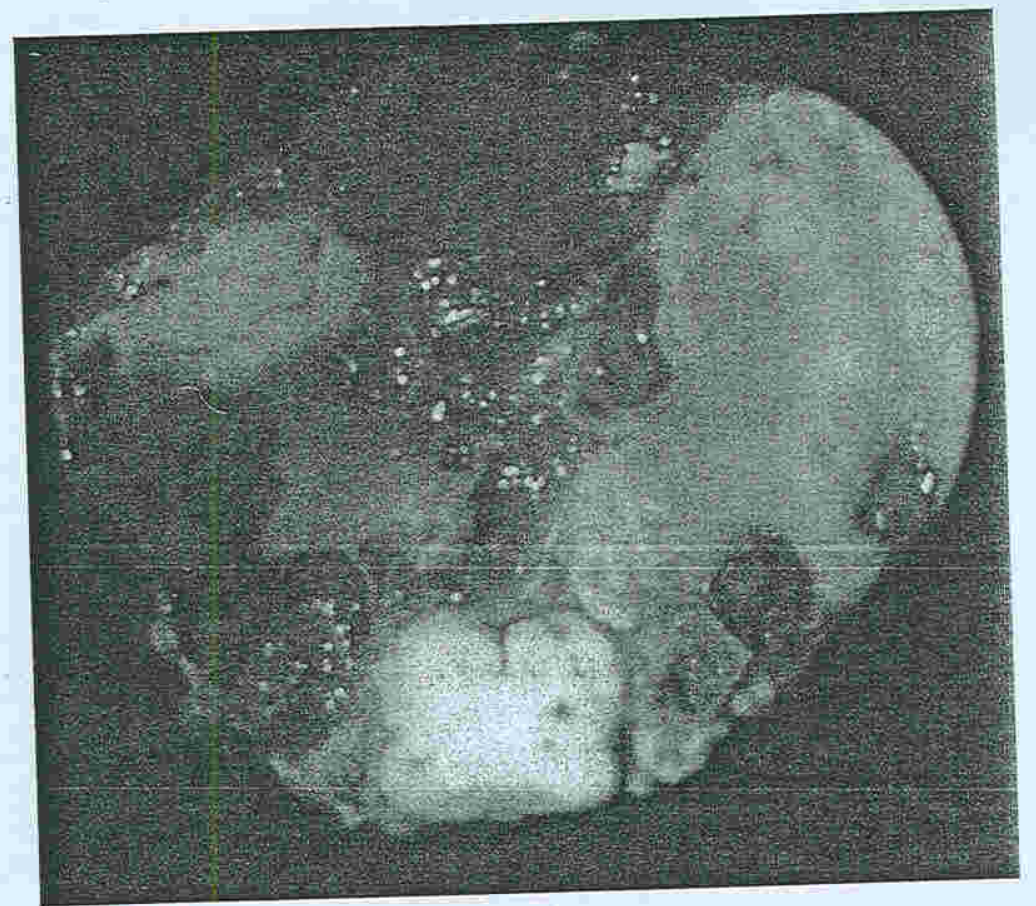

FIGURE 7. Congenital CMV infection. Extensive areas of hemorrhagic necrosis in the cerebellum and cerebral trunk.

asymetry, microgyria, lissencephaly, poroencephaly, and encephalomalacia. Gliosis secondary to necrosis around the aqueduct of Sylvius may cause narrowing or obstruction of the aqueduct, resulting in a triventricular hydrocephalus. The CMV encephalitis involves the gray as well as the white matter and may consist of focal accumulations of microglial cells associated with extensive necrotic areas. The lesions predominate in the periventricular areas of the lateral ventricles but may extend to the ependymal epithelium and choroid plexus. The necrotic areas are later replaced by gliosis and calcification. Periventricular calcification constitutes a radiologic pattern suggestive of CMV infection but it may occur in other areas of the brain. A complete desorganization of the cerebellar cortex, with adherence of gyri is seen in Figure 8. Typical cytomegalic inclusions may be observed throughout the GNS [11].

Other abnormalities present in CMV infection are retinochoroiditis and inflammation of the optic nerve and auditory structures. Many ocular deformities may constitute sequelae of lesions that occurred early in intrauterine life, such as colobomas, microphthalmia, and cataract [11].

Evidence of dysmaturity and interstitial infiltration of lymphocytes and plasma cells are found in the lungs. Cells of the alveolar wall and bronchial epithelium may contain viral inclusions. 


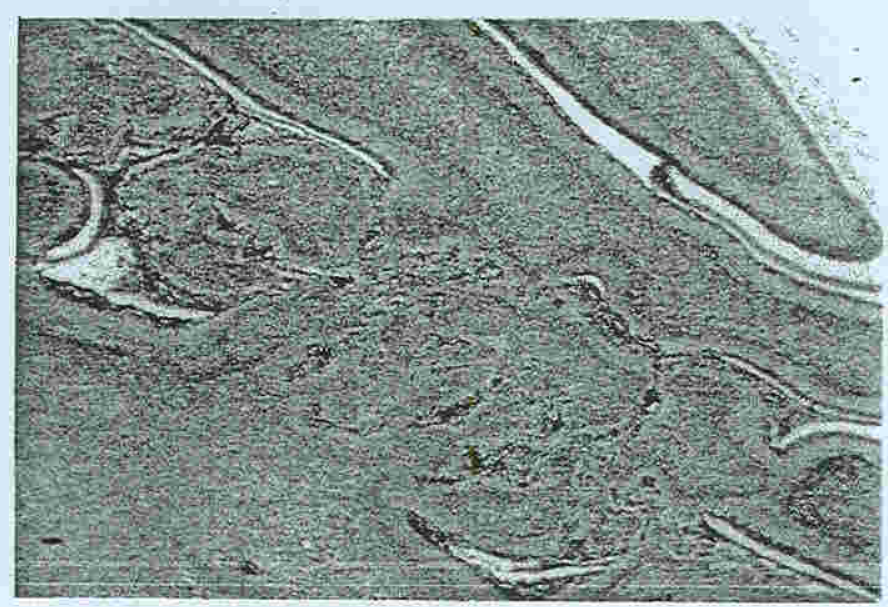

FIGURE 8. Congenital CMV infection. Cortical cerebellar with adherences between the folia and desorganization of the tissue $(\mathrm{H} \& \mathrm{E}, \times 125)$.

Hepatosplenomegaly frequently is observed. Areas of necrosis, sometimes with desorganization of the hepatic architecture, may be seen in the liver associated with portal inflammatory infiltration. The inflammation may cause destruction of the biliary ducts resulting in cholestasis due to paucity of the intrahepatic biliary ducts. Hepatic CMV infection may be associated with extramedullary hematopoiesis, fibrosis, cholestasis, and iron deposition in hepatocytes. Iron deposition also may be seen in other organs [13]. The spleen shows extramedullary hematopoiesis, congestion, and diminished size of the lymphoid follicles [11].

Enterocolitis due to congenital CMV infection may cause multiple strictures, ulceration, and perfuration. The intestinal involvement may constitute the only manifestation of congenital CMV [14].

Cytomegalic cells are frequently seen in the renal tubules (Figure 9), especially in the distal convoluted tubules and the collecting ducts, associated with an interstitial inflammatory infiltrate. Inclusions may also be detected in many other organs. Extramedullary hematopoiesis is also observed in the kidneys [11].

The diagnosis of CMV infection is made by the identification of the typical inclusions as well as taking into account the maternal serologic data. In cases without the typical inclusions, the presence of the CMV can be demonstrated by immunohistochemistry or in situ hybridisation using monoclonal antibodies or specific probes anti-CMV. These techniques can be performed in fresh and in paraffin-embedded tissues. According to Lack et al., the diagnostic yield of immunohistochemistry using monoclonal antibodies to immediate early antigens in equal to or perhaps greater than that of in situ hybridization for active CMV infection [12]. 


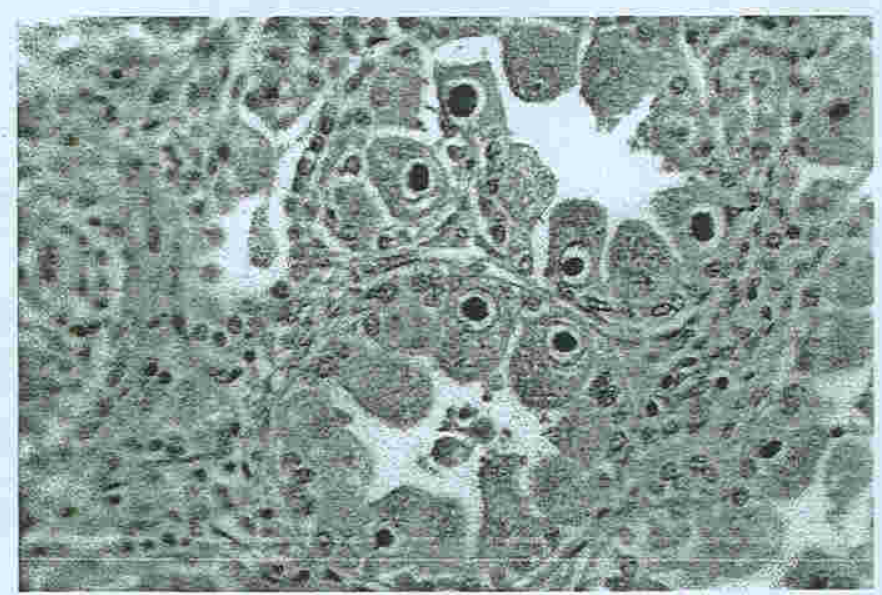

FIGURE 9. Congenital CMVinfection. Renal tubules with viral inclusions type oul-eye (H\&E, $\times 560$ ).

\section{HIV-1 INFECTION}

HIV-1 transmission from mother to child can occur in utero, intrapartum, or postnatally. Estimates indicated that $35 \%$ of cases were infected in utero [15]. However, zidovudine treatment of mothers was associated with a reduction in the transmission rate of nearly $66 \%$ [16].

Infection of the placental villous macrophages has been well documented. These cells may enter the fetal circulation and infect circulating fetal cells or endothelial cells [17].

No manifestations of HIV-l infection are observed at birth. Tovo et al. followingup 529 infected children observed that $81.8 \%$ of them developed acquired immunodeficiency syndrome (AIDS) at a median age of 5 months [18]. The manifestations of AIDS will not be treated in this article.

Some transplacentally acquired infections present a higher frequency of vertical transmission when there is HIV co-infection [19-21]. Investigators have observed that the frequency of congenital syphilis among infants born to HIV-seropositive women is almost 50 times that of the general population [20]. The prevalence of congenital CMV in children born to HIV-infected mothers is $6.4 \%$ higher than the prevalence in the general population [21]. Zanetti et al. followed up 116 babies of Hepatitis C Virus (HCV) positive mothers and only the mothers co-infected with HIV transmited the HCV infection: 5 babies were only infected with $\mathrm{HCV}$ and 3 others were co-infected with HCV and HIV [19].

Some HIV-infected babies that manifest symptoms of tuberculosis, syphilis, and $C M V$ infection in the neonatal period subsequently present rapidly progressive HIV-1 infection and early death [22]. In addition, there are reports of co-infection $\mathrm{HIV} / \mathrm{CMV}$ and HIV/toxoplasma causing devastating CMV infection and toxoplasmosis in the newborn $[23,24]$. 


\section{VIRAL HEPATITIS}

$\mathrm{A}, \mathrm{B}, \mathrm{C}, \mathrm{D}$, and $\mathrm{E}$ types of hepatitis virus are grouped together because their target organ is the liver. To date no consistent relationship between hepatitis $G$ virus (HGV) and acute or chronic liver disease has been demonstrated [25]. Transplacental transmission of hepatitis $\mathrm{B}$ virus ( $\mathrm{HBV}$ ) and hepatitis $\mathrm{C}$ virus (HCV) has been well documented [26-28]; however, the vertical transmission may also occur at the time of delivery or postnatally. Reports about transplacental transmission of hepatitis A virus (HAV), hepatitis $\mathrm{E}$ virus (HEV), and $\mathrm{HGV}$ are rare [29-31].

Sharma et al. found transplacental transmission of $\mathrm{HBV}$ in $50 \%$ of $\mathrm{Hbs} \mathrm{Ag}$ positive mothers [27]. The frequency of vertical transmission of $\mathrm{HBV}$ is higher when acute hepatitis occurs in the third trimester [32]. Once infected, infants usually remain $\mathrm{HBsAg}$ carriers indefinitely. The transplacental transmission of HBV may occur in successive gestations [26].

$\mathrm{HBV}$ is a hepadnavirus that causes acute or chronic hepatitis but many HBV-infected individuals are asymptomatic carriers. Chronic hepatitis may develop into cirrhosis. Furthermore, HBV plays an important role in the development of hepatocellular carcinoma. Recently, through molecular studies, HBV has been incriminated in the genesis of congenital or early acquired cataract [33].

The infected hepatocyte may harbor $\mathrm{HBs} \mathrm{Ag}, \mathrm{HBcAg}$, and $\mathrm{HbeAg}$, antigens that can be demonstrated in tissues by immunohistochemistry. $\mathrm{HBsAg}$ is synthesized during viral replication but may be synthesized in the absence of viral replication. The HBeAg is usually detectable when a large quantity of viral replication is taking place. Vertical transmission is much lower in HBsAg-positive-HBeAgnegative mothers than in HBeAg-positive mothers [34].

Molecular studies have shown that besides the liver, other organs may be infected with HBV, notably lymphoid tissues. HBV does not directly affect hepatocytes. There is much evidence that the main mechanisms of liver cell damage are immunologic resulting in hepatic necrosis and inflammation. [35].

The pathogenesis of liver damage in HCV remains speculative. A body of evidence indicates that the pathologic lesions result mainly from an interaction of the patient's immune system with hepatocytes displaying viral antigens on its surface [35].

The risk of vertical HCV transmission is higher in infants of HCV-positiveHIV-positive mothers. In a wide review of the literature about the frequency of mother-to-infant HCV transmission that included 77 studies, Yeung et al. concluded that the rate of transmission of HCV is $22.1 \%$ among HIV coinfected mothers and only $4.3 \%$ among HIV-negative women [36]. Another risk factor for increasing the vertical transmission rate of HCV is maternal viremia greater than $10^{6}$ copies $/ \mathrm{ml}$ [36]. It has been observed that HCV-RNA detected in the newborn blood soon after birth may disappear later [36, 37]. This fact has been observed in $17 \%$ of all reported cases of HCV vertical transmission 
and could be interpreted as either clearance of HCV infection or transient viremia [36].

Most infants vertically infected with $\mathrm{HCV}$ are asymptomatic. However, only a few of these infants underwent liver biopsy, and most of the biopsies showed evidence of chronic hepatitis. In Egypt a worse outcome was observed. In the follow up of $20 \mathrm{HCV}$-RNA positive infants, 4 died of severe liver disease by 6 months of age, and the remaining were chronically sick with liver disease [36].

Fetal infection in HAV is rare. Leikin et al. described fetal ascitis and subsequent meconium peritonitis in a fetus whose mother developed hepatitis $\mathrm{A}$ at 20 weeks gestation. The infant did well [29].

Vertical transmission of HGV generally occurs in mothers co-infected with HIV or HCV [30], but HGV does not seem to induce hepatitis in children [38].

Khuroo et al. detected HEV-RNA by PCR in cord or birth blood samples of 5 newborns [31]: 1 baby was icteric at birth and 2 presented elevated ALT that suggested anicteric hepatitis. The other 2 were hypothermic and hypoglycaemic and died within $24 \mathrm{~h}$ of birth. Postmortem liver biopsy in one revealed massive hepatic necrosis.

\section{Pathology}

Among $\mathrm{HBsAg}$-positive neonates an increase in the frequency of prematurity and low-birthweight is observed $[26,34]$.

Liver biopsies of perinatally infected children, probably including some congenital cases, show an intact limiting plate and lobular architecture and small foci of parenchymal cytolysis that contain inflammatory cells. The hepatocytes are uniformly hydropic effacing the liver cord architecture and imparting a cobblestone appearance to the parenchyma. Less frequently, fibrosis without bridging is observed [32].

Severe or fatal hepatitis $B$ in the neonate rarely has been described; it may be more likely to occur when the mother is an asymptomatic HbsAg carrier [26, 34]. Lachaux et al. described a case that developed a cholestatic giant cell hepatitis that persisted until death at the age of 5 months [26]. A case of intrauterine infection by $\mathrm{HBV}$ associated with nonimmunologic fetal hydrops has been described. The mother suffered from an acute HBV infection and was Hbs Ag- and HbeAgpositive [39].

Demonstration of $\mathrm{HBsAg}$ in liver biopsies either by specific immunohistochemical or by nonimmunologic methods such as orcein or Victoria blue stain serves to distinguish the ground-glass hepatocytes of chronic $\mathrm{HBV}$ infection. $\mathrm{HBsAg}$ is observed in chronic hepatitis and only rarely in the acute type of hepatitis. Molecular hybridization techniques also demonstrate the presence of HBV-DNA in the hepatocytes [26].

HCV antigens and the HCV genome have been demonstrated in liver tissue biopsy, but the reagents are not currently suitable [35]. 


\section{VARICELLA ZOSTER INFECTION}

Varicella zoster virus (VZV), a member of the Herpesiviridae family, causes a primary and acute chickenpox (varicella) infection and a recrudescent disease, the herpes zoster infection.

The primary infection generally is rapidly controlled by T-cell-mediated immunity; however, when infection occurs in the few days immediately before delivery in a nonimmune mother a risk of developing a disseminated illness exists. If the mother's rash begins more than 4 days before delivery, the infant usually presents only skin lesions because of the transference of specific antibodies [40]. Later, viral reactivation may occur leading to the appearance of a dermatomal exanthem (herpes zoster). The latency period between primary infection and zoster is shorter when varicella occurs in prenatal life. Fetal infection may occur during maternal varicella or maternal herpes zoster; however, it is more frequent in the course of gestational varicella infection [41].

When infection occurs early in gestation, the fetal effect may be catastrophic with the development of a constellation of anomalies known as congenital varicella syndrome. Newborns with acute disease may present with generalized lesions or only a varicelliform rash. Asymptomatic congenital varicella may be recognized by the early occurrence of herpes zoster in infancy [41].

The varicella syndrome consists of a combination of cicatricial skin lesions in dermatomal distribution, eye defects, limb hypoplasia, and defects of the nervous system. The most frequent abnormalities are the cicatricial lesions believed to be the result of intrauterine zoster. Bone abnormalities have been attributable to a neuropathy caused by the direct viral invasion of the dorsal root ganglia and spinal cord; many patients present cerebral cortical atrophy, mental retardation, or both [41].

An extensive neuronal loss from the anterior columns of the spinal cord and complete atrophy of the ganglions corresponding to the distribution of the skin lesions and affected limbs are observed at autopsy. The microscopic findings of the atrophic muscle fibers of the limbs are consistent with denervation changes [42]. Severe involvement of the brain may result in hydrocephalus, extensive cortical atrophy, cystic encephalomalacia, and hypoplasia of the brain stem. Microsopically, a marked destruction of the gray and white matter, areas of cystic degeneration, inflammation, and gliosis along with ulceration of the ventricular lining are observed in these cases $[42,43]$. Extensive necrotic areas with calcification have been described in the brain of a premature infant whose mother had varicella at 7 months of gestation. The lesions involved cortical, subependimal, and basilar cerebral structures and the cerebellar cortex [44]. The cerebral atrophy and the cystic encephalopathy are secondary to a necrotizing encephalitis. The proliferative process following a previous destructive ependymitis is the cause of obstructive hydrocephalus [43]. Massive malformation of the cerebral hemisphere can constitute the only lesion in congenital varicella syndrome [45]. 
In the varicella syndrome widespread lesions can be observed as fibrotic areas or inflammatory changes in the heart, liver, lungs, adrenals, and pancreas [43].

The ocular abnormalities described in order of frequency are chorioretinitis, anisocoria, microphthalmia, and cataract. In the limbs, hypoplasia, absence of digits, talipes equinovarus, or calcaneovalgus have been reported [41].

Ulcerations can be observed in the gastrointestinal tract and are the cause of intestinal fibrosis and strictures that have been described $[42,44]$. Mucosal fibrosis of the trachea and bladder are the result of healed ulcerations [42].

Other aspects not frequently observed in the varicella syndrome are hydronephrosis and hydroureters [42]. Besides motor or sensory defects, survivors may exhibit decreases or absences of deep tendon reflexes, Horner syndrome and anal and vesical dysfunction. These manifestations are the result of cervical or lumbar spinal cord lesions that also are responsible for hypoplasia or aplasia of limbs and digits [41].

\section{Pathology}

In the acute and generalized infection the skin, liver, and lungs (Figure 10) are always involved. Less commonly, lesions are seen in adrenals, digestive tract, thymus, and kidneys (Figure 10). In the skin the lesions are necrotic and hemorrhagic. Histologically the necrotic areas are surrounded by few epithelioid and mononuclear cells but sometimes an inflammatory reaction is not detected (Figure 11). Varicella pneumonitis, fulminant hepatitis, and disseminated intravascular coagulation constitute causes of death of perinatal VZV infection [40]. The skin lesions are similar to those observed in herpes zoster (Figure 12) and herpes simplex, but not in vaccinia [41].
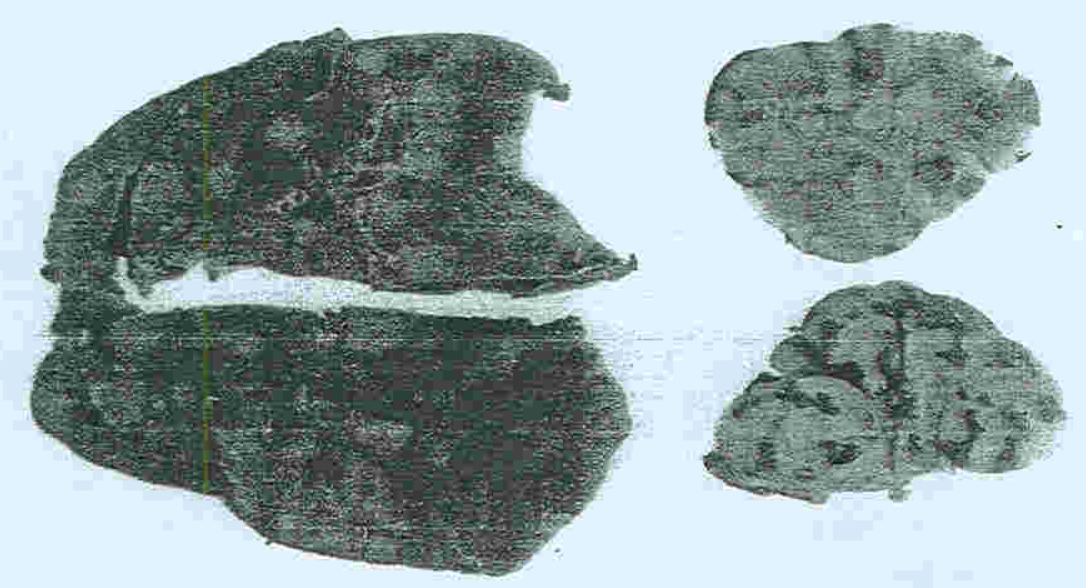

194.

FIGURE 10. Congenital varicella. See multiple areas of necrosis in the lungs and of hemorrhagic necrosis in the kidney. 


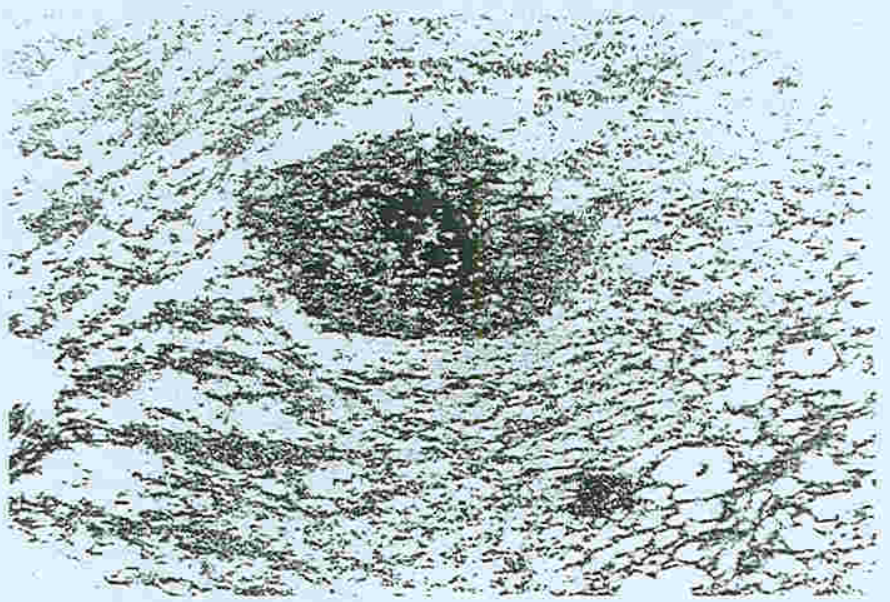

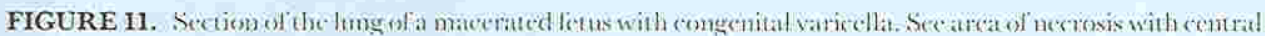
catcilication $(H \& \mathrm{E}, \times 125)$.

The pathologic findings can be confirmed by viral culture or through the demonstration of VZV antigen in fetal organs [40]. Besides detection of the VZV, DNA can be achieved in fetal tissues by PCR [43].

\section{HERPES SIMPLEX}

There are two types of herpes simplex virus (HSV): HSV type $1(\mathrm{HSV}-1)$ and type 2 (HSV-2). They usually infect at different sites. HSV-l causes a primary infection in the oral mucosa (gingivostomatitis) establishing latency in the sensory neurons of the trigeminal ganglion. HSV-1 may also spread along neuronal pathways

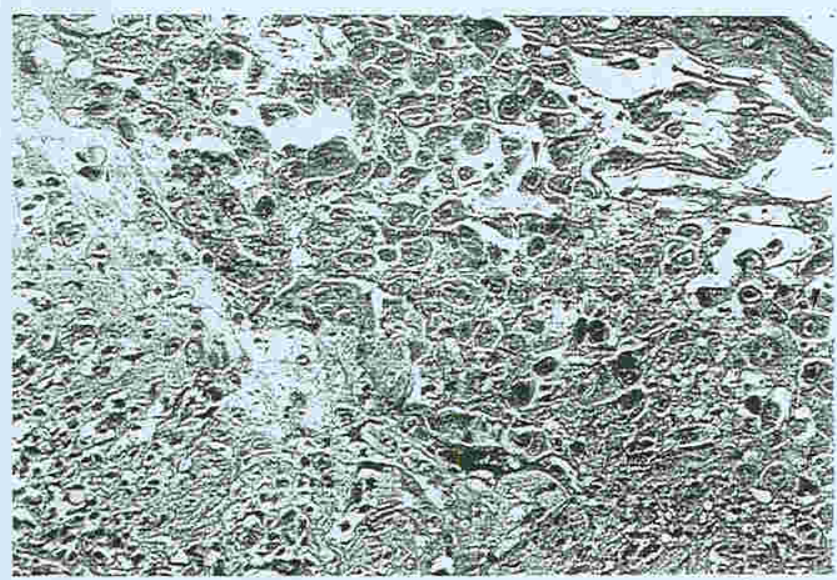

FIGURE 12. Congenital herpes simplex. A multiloculated intraepidermal vesicle with necrotic keratinocytes, some of them with intranuclear inclusions (arrows) ( $\mathrm{H} \& \mathrm{E}, \times 360$ ). 
into the CNS resulting in severe encephalitis. HSV-2 is generally acquired as a sexually transmitted infection. After the primary infection, replication of the virus at the portal of entry, usually oral or genital mucosal tissue, results in infection of sensory nerve endings, and the virus is transported to the dorsal root ganglia, where it establishes a latent infection. Viral replication leads to cellular ballooning and multinucleation and originates intranuclear inclusions [46].

Infection of the fetus or newborn may be acquired in utero, intrapartum or postnatally, although intrapartum transmission accounts in 85-90\% of all cases. Congenital infection is rare and may occur by the ascending or the hematogenous route [46]. Routine placental examination is mandatory to prove the exact means of HSV congenital transmission.

\section{Pathology}

Most of the infected newborns are born prematurely. Infection may also constitute cause of abortion [46]. The disseminated form of infection generally involves liver (Figure 13), adrenals, lungs, brain, and heart. Hemorrhagic necrosis is the predominant aspect observed but lymphocytic infiltration can also be seen. These lesions cause extensive destruction [46]. Secondary to necrosis, extensive areas of calcification can occur (Figure 14).

Intrauterine herpes simplex may appear as cutaneous vesicles or scars, eye lesions, and severe CNS abnormalities such as microcephaly and hydranencephaly. The main ocular changes are keratoconjuntivitis and chorioretinitis. In the skin ballooning degeneration of keratinocytes and intracellular edema are observed in the epidermis leading to the formation of an intraepidermal vesicle [46]. The necrotic keratinocytes present multinucleation and intranuclear inclusions (Figure 12).

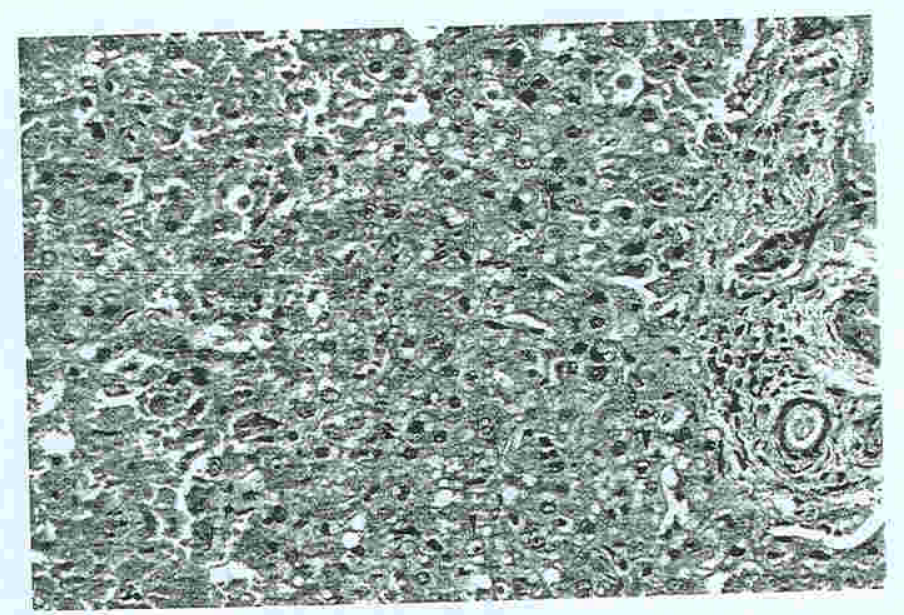

FIGURE 13. Liver in congenital herpes simplex. There are necrotic hepatocytes, some of them presenting intranuclear inclusions. There is a mononuclear infiltration in the portal area (H\&E, $\times 360$ ). 


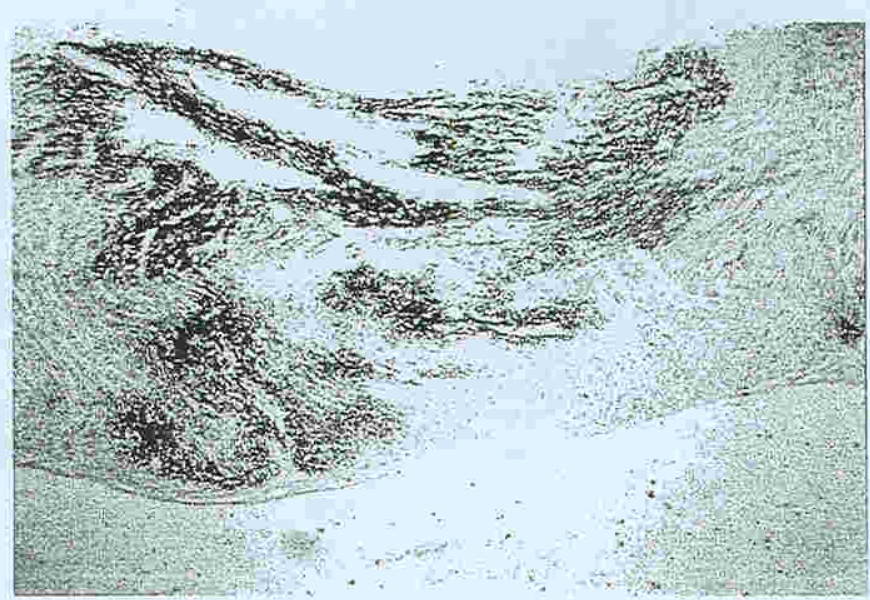

FIGURE 14. An alontus with horpes simplex. An extensive area calcifoation is seen in the endocardium. myouralium, and epicardiun (H\&l; $x+0)$.

The diagnosis can be made through the finding of balloon cells with inclusions in tissues in H\&E stained sections. Viral cultures or typing of HSV-1 and HSV-2 by immunohistochemistry techniques can be used to prove the diagnosis [47]. Herpesvirus DNA may be detected in paraffin sections of formalin-fixed organs by PCR [48].

\section{PARVOVIRUS B19 INFECTION}

Parvovirus is one of the smallest of the DNA viruses that infect mammalian cells. B19 is the only known pathogenic parvovirus in humans. Transmission of the virus occurs in approximately one-fourth to one-third of cases and it may occur at any time during gestation. Parvovirus B19 may be responsible for $7-15 \%$ of all cases of nonimmune hydrops $[49,50]$, intrauterine deaths, and spontaneous abortions, although it is not considered a common cause of congenital abnormalities and neonatal deaths [50].

The presence of a specific cellular receptor, the erythrocyte $\mathrm{P}$ antigen, is considered to be necessary for susceptibility to parvovirus infection. Individuals who do not have this receptor are naturally resistant. P antigen is present not only on erythrocytes and erythoblasts, but also on megakaryocytes, endothelial cells, placental cells, fetal liver, and heart cells that also may be infected [51].

Human erythroid progenitor cells in the bone marrow are the principal target cells, and infection results in lysis and aplasia. The fetus may develop a severe intrauterine anemia and nonimmune hydrops, because fetal erythrocytes have a short survival time and fetal development requires a rapid increase in the erythrocyte pool. The pathologic changes are the consequence of hypoxic damage to multiple organs with increased capillary permeability. Chronic, severe anemia also may increase cardiac output and subsequently result in high output heart failure. Alternatively, myocarditis may precipitate heart insufficiency. Lysis of erythrocytes 
in the liver may cause hemosiderin deposition and fibrosis [50]. When the virus crosses the placenta especially early in gestation, a high risk of fetal death exists, however, fetal infection may be associated with a normal outcome [52] and fetal hydrops may resolve spontaneously [53].

\section{Pathology}

Most of the B-19-associated fetal deaths occur during the second trimester of gestation. The fetuses are generally hydropic and anemic. Visceral pallor and enlargement of the liver and the spleen are the most frequent internal abnormalities. A skin rash called blueberry muffin skin can be rarely observed and represents foci of extramedullary hematopoiesis. The heart may be normal or symmetrically enlarged and the thymus is abnormally small [50].

The characteristic intranuclear inclusions are seen in the erythroid precursors within the lumen of vessels in most organs. In $H \& E$ stained sections, the nuclei present a marginated and darkly stained chromatin and the center of the nuclei is lighter in color with a smooth and glassy appearance. In some inclusions a popcorn profile with blebs of basophilic material projecting from the nuclear surface are observed (Figure 15A). The inclusions can be observed even in macerated fetuses, and are more frequent in the lungs, liver, and brain [54]. Perivascular or diffuse mononuclear infiltration, necrotic foci in skeletal and smooth muscle cells and cardiac cells along with focal vascular endothelium damage have been observed [54-56]. Focal areas of dystrophic calcification and fibroelastosis have been described in the heart $[53,54]$. In the lungs a diffuse or focal interstitial mononuclear

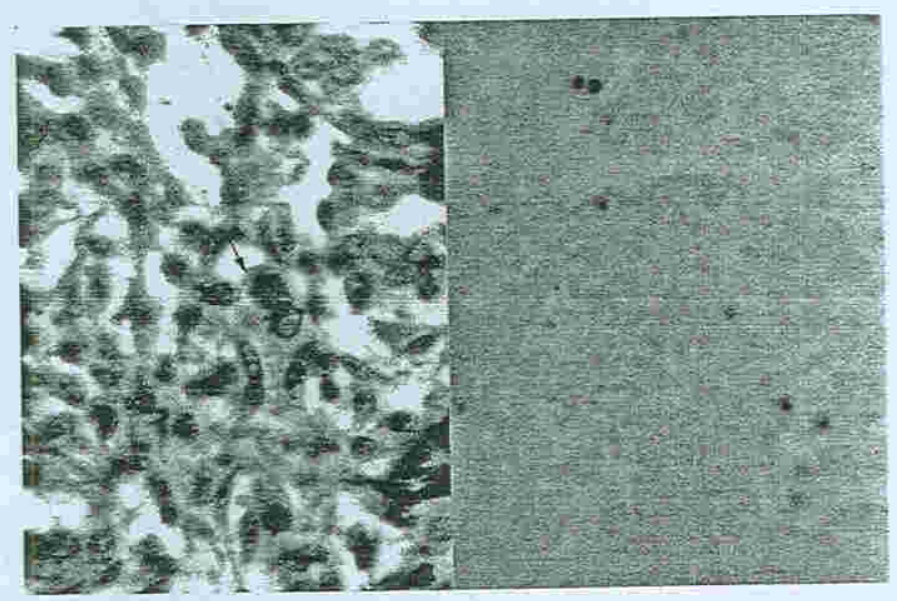

FIGURE 15. Lung of a macerated hydropic fetus with parvovirosis. (A) See in some inclusions (arrow) a pop. corn profile with blebs of basophilic material projecting from the nuclear surface $(\mathrm{H} \& \mathrm{E}, \times 1200)$. (B) The black. dots represent infected cells in alveolar capillaries (In situ hybridization, $\times 560$ ). Courtesy of Dr. Jussara Nascimento. 
cell infiltration constitutes a common finding [54]. The thymus may be decreased in size with lymphocytic depletion suggestive of severe intrauterine stress [53].

In the liver besides an increase in hematopoiesis, erythrophagocytosis and inclusions in nucleated red blood cells frequently are demonstrated [50]. Siderosis associated with portal fibrosis, bile duct proliferation, cholestasis, and focal necrosis also have been described in congenital parvovirus infection [54].

Severe CNS abnormalities after matemal B19 infection have been described in 3 infants following maternal B19 infection [50]. Chronic leptomeningitis, ependimitis, and calcification of vessels in the brain also have been observed [54]. Early infection with B19 virus can cause severe ocular malformations such as microphthalmia, aphakia, absence of the anterior chamber, iris, and lens, retinal folds, and hipoplasy of the retina $[55,56]$. These observations raise the possibility that parvovirus B19 may have teratologic effects on a developing human embryo.

Fetal infection may be diagnosed by finding inclusions in the nucleated red blood cells. However, histologic examination may be unsuccessful in detecting the viral inclusions in one-third of the cases [57]. The virus may be detected by immunocytochemistry, in situ DNA hybridisation (Figure 15B), dot-blot hybridization, or PCR using formalin-fixed paraffin embedded tissues [57, 58]. However, dot-blot hybridization is more efficient than in situ hybridization for detecting B19 DNA [58]. These methods may give positive results even in tissues of macerated fetuses [54].

\section{ENTEROVIRUSES}

The enterovirus is a picornavirus (small RNA virus). Enteroviruses include coxsackie viruses types $\mathrm{A}$ and $\mathrm{B}, \mathrm{ECHO}$ viruses, polioviruses, and other enterovirus types. Although unusual, transplacental transmission has been shown to occur with coxsackie virus, ECHO virus, and poliovirus.

The infectivity of enterovirus is largely determined by the presence of specific receptors on the cell membranes of target tissues. Researchers also have suggested that a sequential loss of receptor-containing cells or of receptor sites on persisting cells with increasing age may be correlated with a decrease of viral pathogenicity in older hosts. However, there are marked differences in regard to tropism and virulence of the different enteroviruses [59]. Pathogenesis of enterovirus is related to its cytolytic effect in the host cells. Infection of susceptible cells leads to cell death and release of infectious viruses causing tissue damage of variable intensity.

Evidence of intrauterine infection has been shown for coxsackie viruses A3, A9, and $B 2-B 4$ and $B 6$ but these cases are rare $[59,60]$. Transplacental passage of coxsackie viruses are generally detected at term [59]; however, this virus also may be responsible for abortion [60]. Coxsackie virus B infection may cause myocarditis, meningoencephalitis, pneumonitis, and inflammatory foci with necrosis in the liver, pancreas, and adrenals [59]. Bates described a case with hydrops and calcified pancarditis caused by B3 coxsackie virus [61]. Pneumonitis and mild myocarditis have been found in $\mathrm{A} 3$ and $\mathrm{A} 9$ congenital coxsackie virus infection $[62,63]$. 
ECHO virus (enteric cytopathogenic human orphan virus) is subdivided into 31 different sorotypes that include $1-7,9,11-27$, and 29-34. The ECHO viruses $9,11,27$, and 33 have been associated with infections transplacentally acquired [ 59 , 64-677. Garcia et al. described 3 cases (2 abortions and 1 stillbirth) of congenital infection with $\mathrm{ECHO}$ virus types 27 and 33 [64]. The virus was isolated from fetal organs that presented necrosis (Figure 16) and hemorrhagic foci. Pneumonitis has been described in a case of congenital $\mathrm{ECHO}$ virus infection type 9 [67]. In congenital ECHO virus type 11, autopsy studies have shown hepatic fibrosis with regenerative nodules, adrenal hemorrhagic necrosis, and foci of myocardial, hepatic, and adrenal calcification [65]. Congenital ECHO virus infection type 11 also may present pneumonia associated with pulmonary hypertension and generalized maculopapular exanthem $[66,68]$.

Poliomyelitis is associated with an increased incidence of abortion. In an abortus isolation of poliovirus type I from both the placenta and the fetal tissues was obtained 12 days after the onset of illness in the mother [59].

The histopathologic diagnosis of ECHO virus and coxsackie viruses is accomplished by identification of the viral antigens by immunocytochemistry in paraffin-embedded tissue samples. Virus particles also can be visualized by electron microscopy (Figure 17). Isolation of ECHO viruses from placental and fetal tissues also can be performed [64].

\section{TOXOPLASMOSIS}

The tachyzoites are the parasitic forms of Toxoplasma gondii present at the onset of infection. They represent the proliferative forms of the parasite and are responsible for parasitemia and the development of lesions. The tachyzoytes are crescentic or oval organisms, $2-4 \mu \mathrm{m}$ in diameter and $4-8 \mu \mathrm{m}$ long. They can penetrate any cell

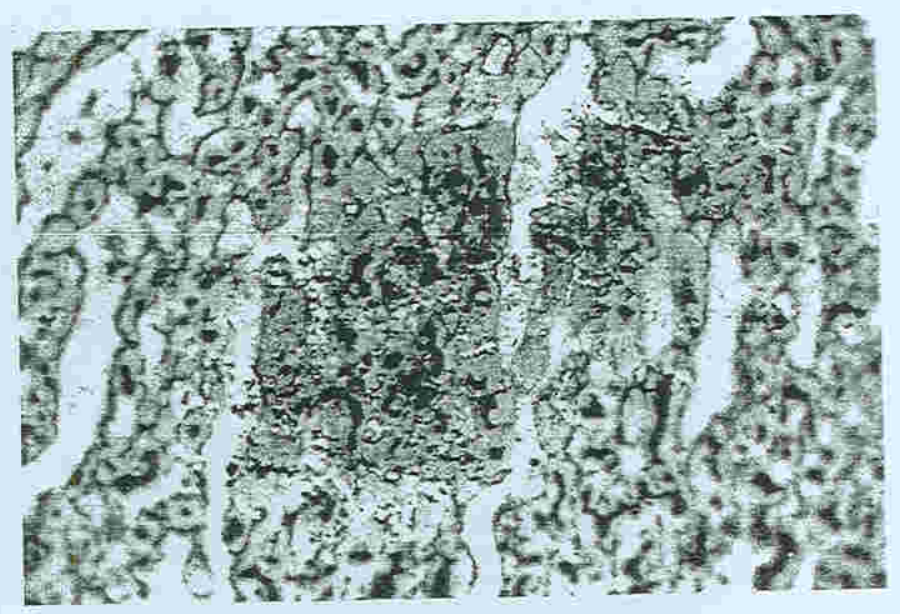

FIGURE 16. ECHO virus infection. Area of necrosis in adrenal (H\&E, $\times 560)$. 


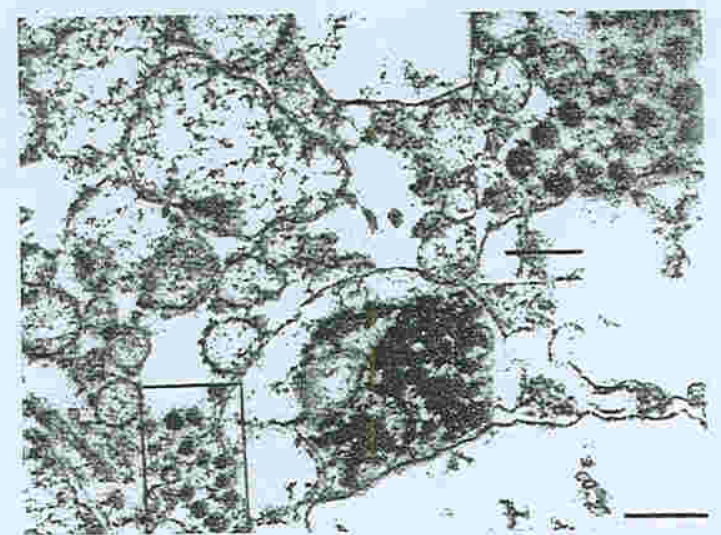

FIGURE 17. ECHO virus 33 infection. Viral particles ( $30 \mathrm{~mm}$ ) are seen in the degenerated cytoplasm of a hepatocyte. Bar $=200 \mathrm{~nm}$. Inset: $100 \mathrm{~nm}$. From Garcia, et al., J Pathol 1990;160:123-127.

where they multiply. After rupture of the cell, they enter in another cell or into the fetal bloodstream. When cellular rupture does not occur, cysts of bradyzoites are formed containing up to 3000 parasites [69]. When the host develops a $\mathcal{T}$. gondii immune response, the parasitemia and the clinical manifestations disappear and the cysts remain in various tissues, preferentially in the brain, eyes, and skeletal and cardiac muscles, constituting the chronic or latent form of infection. Nonetheless, cysts also are found in the acute phase of the disease.

The remission of toxoplasmic infection depends on the development of humoral and cellular immune responses. However, the lesions have a protracted evolution in tissues with difficult access of antibodies such as the CNS and eyes. The acute phase of the disease can reappear if the host develops a state of immunosupression [69].

Since the majority of pregnant women are infected during the third trimester, about two-thirds of newborns present the subclinical form of infection. This form has the potential of manifesting symptomatology later. Nonetheless, the severe sequelae of the encephalic form may be present at birth.

\section{Pathology}

The leptomeninges are thickened. Foci of necrosis and/or calcification are commonly seen throughout the CNS (Figures 18 and 19). In cases of extensive necrosis, flattening of the giri, asymmetry of the cerebral hemispheres, and dilatation of the ventricular system are observed. When hydrocephalus is severe, extreme atrophy of the cerebral parenchyma may be seen with complete disappearance of the cerebral substance in many areas [69]. Hydranencephaly also has been described in the encephalitic form of infection [70].

The parasites cause perivascular inflammation and vasculitis with later development of necrosis and calcification. The infiltrate consists of lymphocytes, plasma cells, macrophages, neutrophils, and less frequently eosinophils. Large areas of 


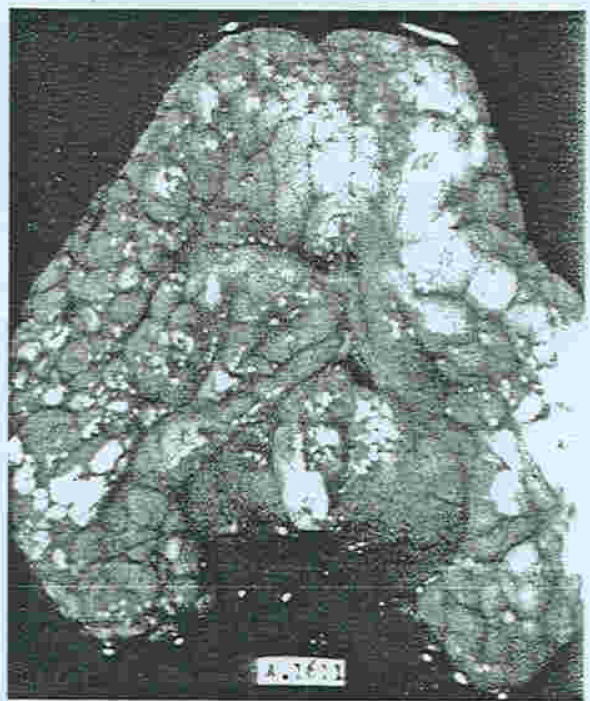

FIGURE 18. Cogenital toxoplasmosis. The milky areas in the cerebral surface correspond to necrosis and calcification

necrosis can be the result of vascular thrombosis secondary to vasculitis. Acute toxoplasmosis is manifested as the encephalitic or systemic form, but the CNS is never spared $[69,71]$.

Necrosis represents the most characteristic lesions in the CNS (Figure 20). The necrotic lesions are more marked in the cerebral cortex, basal ganglia, and periventricular areas. Later on the lesions became calcified or transform into cavities.

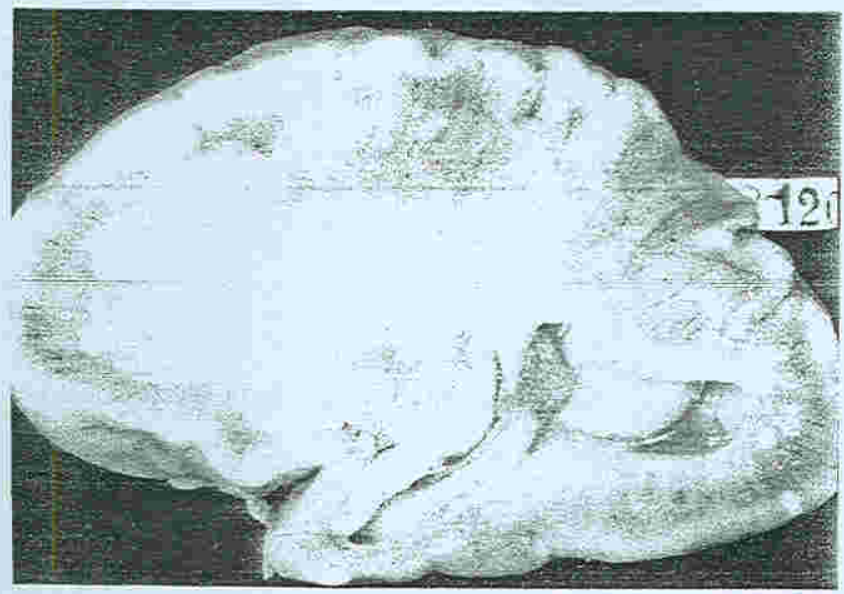

FIGURE 19. Congenital toxoplasmosis. See a longitudinal section of the brain with mild ventricular dilatation and areas of necrosis and calcification in the cortical, medullar, and periventricular area. 


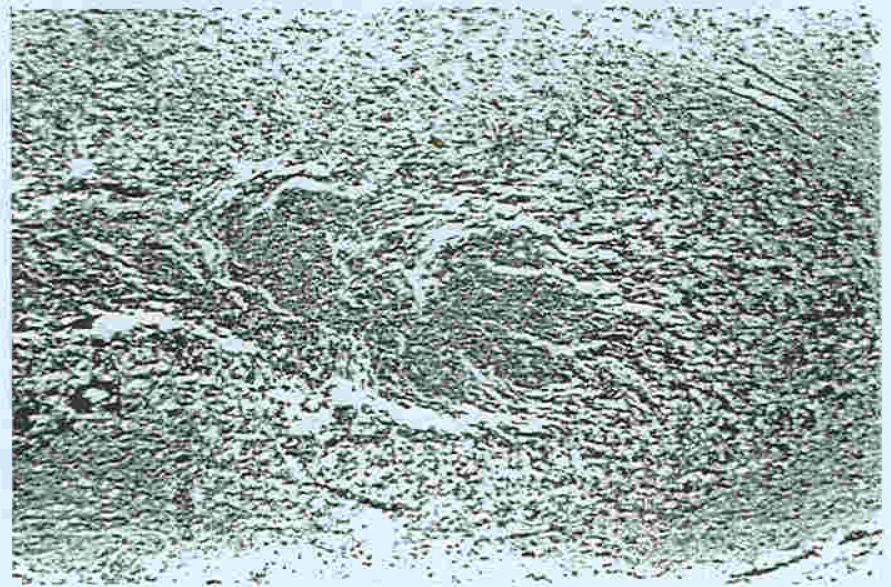

FIGURE 20. (ingenital toxejplasnesis. Area of ncressis in the lorain surrounded loy menonuelear infileration.

Besides necrosis, foci of microglial proliferation are seen throughout the CNS. Leptomeningitis and ependymitis are also observed. Inflammation and necrosis, when present around the aqueduct of Sylvius, may cause obstruction and hydrocephalus. Nonetheless, hydrocephalus also can be due to extensive periventricular necrosis. Tachyzoites and cysts are present in the lesions and in the neighboring normal tissues as well as in the intima of the vessles $[69,71]$.

In the eyes retinochoroiditis, retinal necroses, disruption of the retinal pigment epithelium, and optic neuritis are characteristic findings. T-cells predominate in retinal lesions and choroid. By immunohistochemistry parasites were frequently identified in the lesions [72]. Other changes such as iridocyclitis and cataracts are secondary to retinochoroiditis. Microphthalmia and eye disruption can be observed in cases with severe infection. Parasitized lesions also have been observed in the mastoid and inner ear, and they are certainly responsible for the hearing loss observed in congenital toxoplasmosis [69].

An interstitial infiltrate of mononuclear cells is observed in the lungs and also in the wall of the small pulmonary vessels. Parasites can be found in the alveolar lining cells (Figure 21), in the endothelium of pulmonary vessels, and free within alveoli [69].

The heart, second only to the brain and the eyes, is commonly affected. Cysts of toxoplasma without any inflammatory response may be observed in the myocardium, but after the rupture of the cysts an inflammatory infiltrate occurs. Hyalin necrosis of cardiac myofibers may be seen with the inflammatory reaction. Inflammation is also observed in the endocardium and epicardium. Extensive areas of calcification rarely are present in the heart [73].

A marked erythropoiesis may occur in the spleen, liver, and kidneys and are commonly seen in autopsies of infected stillbirths and neonatal deaths. In the liver, a portal infiltrate of mononuclear cells, neutrophils, and eosinophils along with 


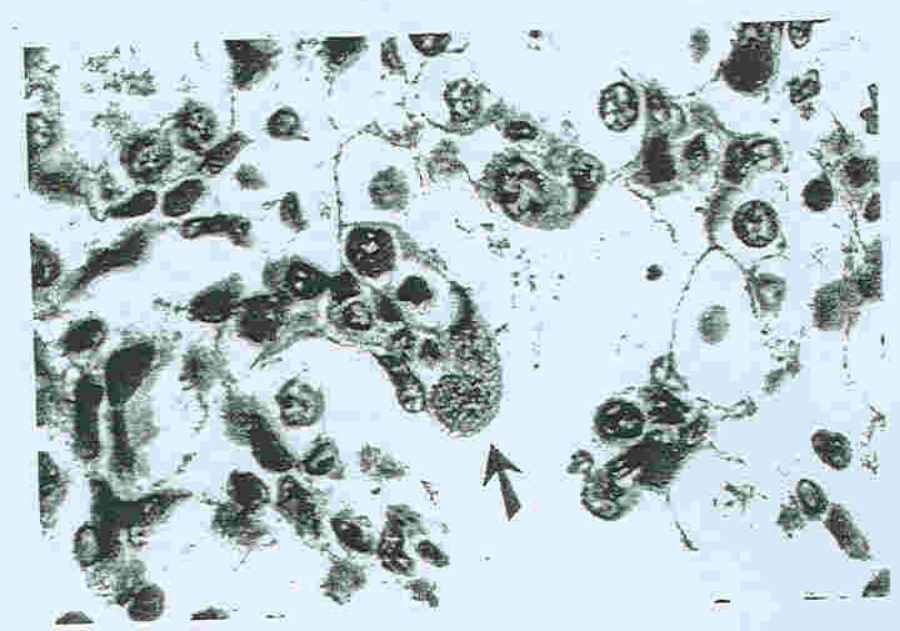

FIGURE 21. Toxoplasma pneumonitis. A toxoplasma cyst is seen in a cell of the alveolar wall. Mononuclear cells are observed in the septum $(\mathrm{H} \& \mathrm{E}, \times 560)$.

focal necrosis and parasitized Kupffer cells may be observed. Less frequently, giant cell hepatitis is present $[69,74]$. Glomerular and tubular necrosis may be seen in the kidneys. However, toxoplasma cysts have also been found in glomeruli and renal tubules without associated lesions. The adrenals show focal or segmental necrosis, parasitism, and inflammation. Parasitized lesions may be seen in any tissue in the systemic form of toxoplasmosis [69].

The presence of the I. gondii (tachyzoites or cysts) in tissues confirms the histopathologic diagnosis of congenital toxoplasmosis. The cysts are strongly positive with PAS; however, the cyst wall stains weakly with PAS but it is strongly argyrophilic. The toxoplasma may be histologically misdiagnosed as amastigotes (the tissue forms of I. cruzi). However, the amastigotes present, besides the nucleus, the kinetoplast, a structure that is not present in toxoplasma. In cases of doubt, immunohistochemical identification of parasites using paraffin-embedded sections and antitoxoplasma or anti-Trypanosoma cruzi antibodies are confirmatory. To differentiate toxoplasma from Histoplasma capsulatum, a silver stain with Grocott method must be used.

Diagnosis of congenital toxoplasmosis also may be made by in situ hyrbidization or PCR using formalin-fixed paraffin-embedded tissues. The isolation of the parasite from tissue or body fluid by means of cell culture or animal inoculation are other methods to detect toxoplasma in autopsy material. However, PCR assay produces more positive results than the other methods [75].

\section{CHAGAS' DISEASE (AMERICAN TRYPANOSOMIASIS)}

T. cruzi presents in the mammalian host in two morphologically distinct forms: the trypomastigotes and the amastigotes. The trypomastigotes are motile, 


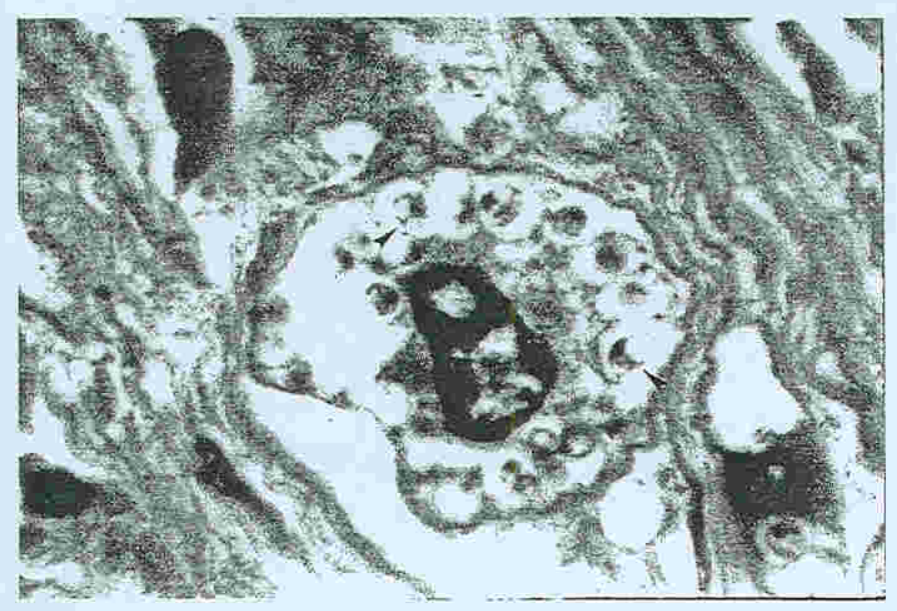

FIGURE 22. (omgenital Chagas disease. Parasilized giant coll full ol amastigotes. Ser the cinctoplast and the metersol the parasite (arow) (H\&D, $\times 1250$ ).

spindle-shaped, and nonmultiplying blood forms of the parasite. Intracellularly they are transformed into amastigotes (Figure 22) that multiply and are later released as trypomastigotes upon lysis of the infected cells. The trypomastigotes enter other cells, initiating a new cycle or they penetrate the fetal bloodstream disseminating the infection. The trypomastigotes are present in the blood during the acute phase of the disease but thereafter, in the chronic phase of the infection, parasitemia is intermitent.

At the onset of the infection, trypomastigotes invade mononuclear phagocytes. However, later the parasite becomes almost completely confined to the muscle tissues. Other cells also may be parasitized such as glial cells, fibroblasts, Schwann cells, neurons, and cells of the trophoblast and amniotic epithelium. After rupture of the parasitized muscle cell, an inflammatory infiltrate appears that is initially multifocal and related to the presence of the parasite. Later the inflammatory infiltrate becomes diffuse in the heart. In this organ, the inflammation may extend to the conducting system, nerves, autonomic nervous system ganglia, endocardium, and pericardium [76].

The occurrence of a severe inflammatory infiltration in structures without regenerative capacity such as the conducting myocardial fibres, myenteric plexuses, and CNS may result in scars whose clinical consequences are generally of late appearence [76].

After the acute phase of infection that lasts a few months, the great majority of patients progress to the indeterminate phase (without symptomatology), that may last 10-20 years or may persist indefinitively. Later, in adulthood, infected individuals may develop cardiac, digestive, or nervous chronic forms of the disease. The digestive and nervous forms are believed to represent sequelae of lesions that have 
occurred during the acute phase. However, chronic myocarditis constitutes a lesion of late onset [76].

In the congenital form of disease, sequelae of the digestive and CNSlesions can appear very early immediately after, or even during the acute phase. The severity of the inflammatory process and the immunologic immaturity of the host are responsible for these early manifestations $[76,77]$.

\section{Pathology}

Stillborns and newborns with severe disease may present hydrops and hepatosplenomegaly. When the conceptus dies of cardiac insufficiency, cardiomegaly is observed. Parasites may be detected in the majority of the organs, but they predominate in the brain, heart, esophagus, intestines, skeletal muscles, and skin. The inflammatory infiltrate consists of mononuclear cells with some neutrophils, and less commonly small granulomas of epithelioid cells are seen [78].

The microscopic features of congenital Chagas' disease are in many aspects similar to those observed in the noncongenital acute phase of the disease. However, the congenital disease may present aspects not observed in the noncongenital acute disease such as parasitized giant cells with a single hyperchromatic nucleus (Figure 22), pneumonitis, subepidermal granulomas, and early digestive and neurological manifestations [78].

The inflammatory infiltration in the myocardium in generally diffuse and is associated with edema and disruption of the myofibres (Figure 23). The inflammation may extend to other structures of the heart. Parasitism and necrosis of myofibres are frequent findings. Mononuclear cells can be seen attached to or inside myofibres [76].

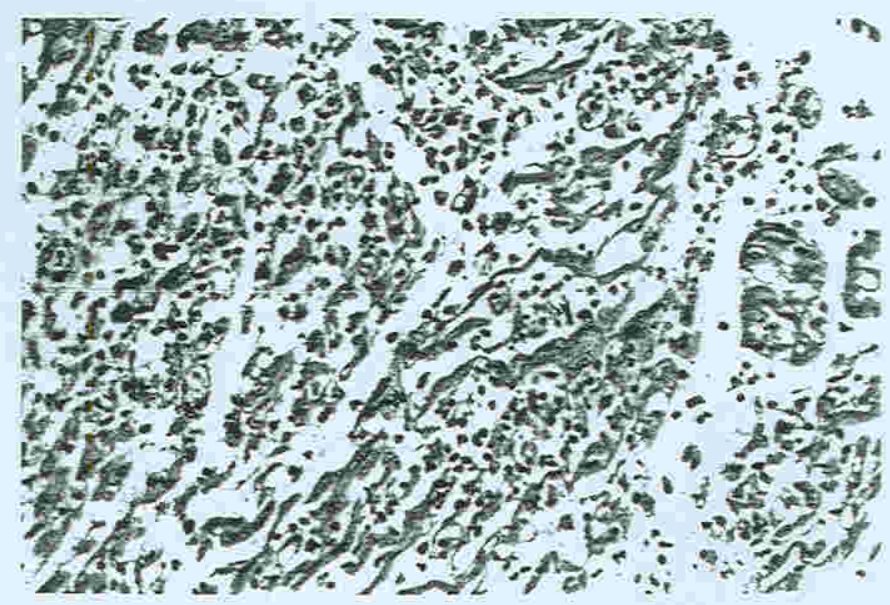

FIGURE 23. Congenital Chagas' disease. A marked myocarditis with edema, mononuclear infiltration, and necrosis of miofibers. See one parasitized miofiber (arrow) (H\&E, $\times 360)$. 


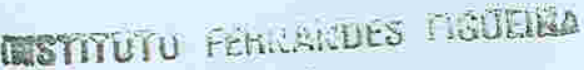 gihlitices?}

Chagasic encephalitis consists of perivascular chronic inflammatory lesions that are more commonly seen in the brain. The lesions consist of proliferation of microglial cells, lymphocytes, plasma cells, and parasitized cells frequently associated with a meningeal mononuclear infiltration. The lesions may be subependymal with destruction of the adjacent epithelium [79].

The muscular layer and Auerbach's plexus of the esophagus and intestines show a marked focal inflammatory infiltration with parasitism of myofibres or macrophages (Figure 24). Degeneration or destruction of neurons may be observed in the Auerbach's plexus. These alterations are responsible for early digestive manifestations (regurgitation, vomiting, and dysphagia) and megaesophagus (Figure 25) [76].

In the lungs, besides mononuclear infiltration in the interalveolar septa, parasitized cells can be observed in the alveolar wall or inside the alveolus (Figure 26) [78].

Disseminated erythematous lesions, petechiae, and nodules may be observed in the skin. Microscopically, vasculitis and panniculitis with infiltration of neutrophils, lymphocytes, and plasma cells are observed. There is also frequent involvement of the skeletal muscles [79].

Miliary granulomas composed of mononuclear cells, epithelioid cells, and parasitized macrophages may be observed in the liver. Foci of necrosis and fibrosis also have been described in this organ. The lymph nodes and spleen are enlarged and present macrophage proliferation sometimes associated with parasitism. Lymphocytic depletion in the thymus is also observed [79].

The histopathologic diagnosis of congenital Chagas' disease is made by finding amastigotes in H\&E-stained preparations. They are spherical or oval, are $2 \mu \mathrm{m}$ in diameter, and present a nucleus and kinetoplast. The kinetoplast consists of a deeply stained parabasal body and an adjacent dot-like blepharoplast (Figure 22). Immunocytochemistry is superior to that of conventional examination for detecting

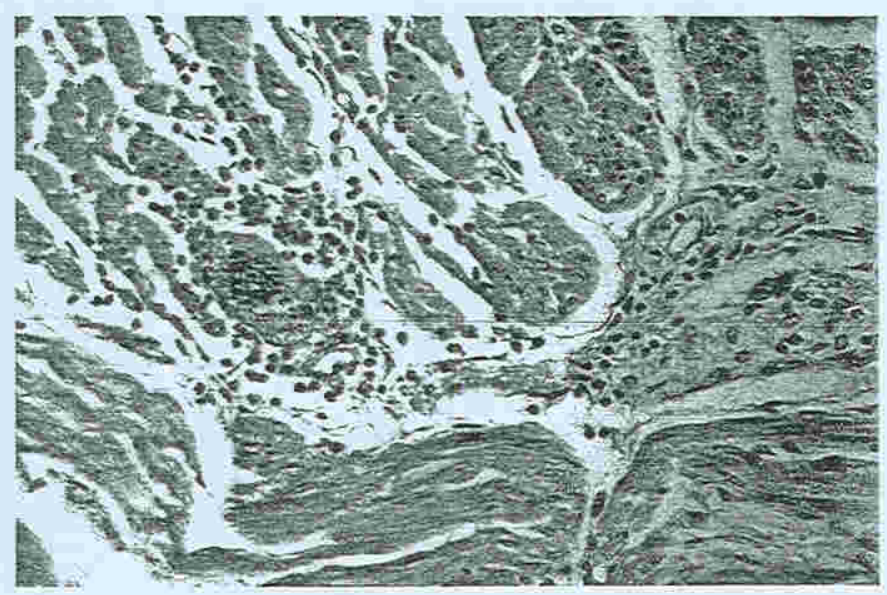

FIGURE 24. Esophagus in congenital Chagas' disease. See a giant parasitized cell with a huge and hyperchromatic nucleus near the Auerbach plexus. There is inflammatory reaction in the plexus and around the giant cell (H\&E, $\times 560)$. 


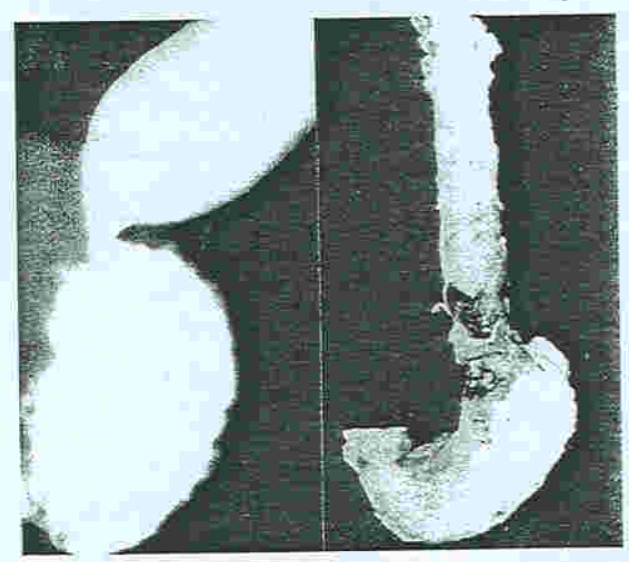

FIGURE 25. Congenital Chagas' disease. The radiologic and macroscopic aspect of a congenital chagasic megaesophagus with digestive manifestations since birth.

amastigotes in tissues and also enables the differential diagnosis of toxoplasma and Histoplasma capsulatum [76].

\section{MALARIA}

Congenital malaria may be caused by Plasmodium vivax, $P$ malariae, P. ovale, and P. falciparum; however, it is of rare occurrence. Its rarity may be partially explained by late onset of symptomatology. Thus, its late manifestations can be misinterpreted as a postnatal acquired infection. Even in infants born to mothers with low levels of immunity, symptoms of congenital malaria are usually delayed until 4-12 weeks after birth [80]. It is believed that fetal hemoglobin protects the fetus against malarial infection, and for this reason the morbidity of this infection is

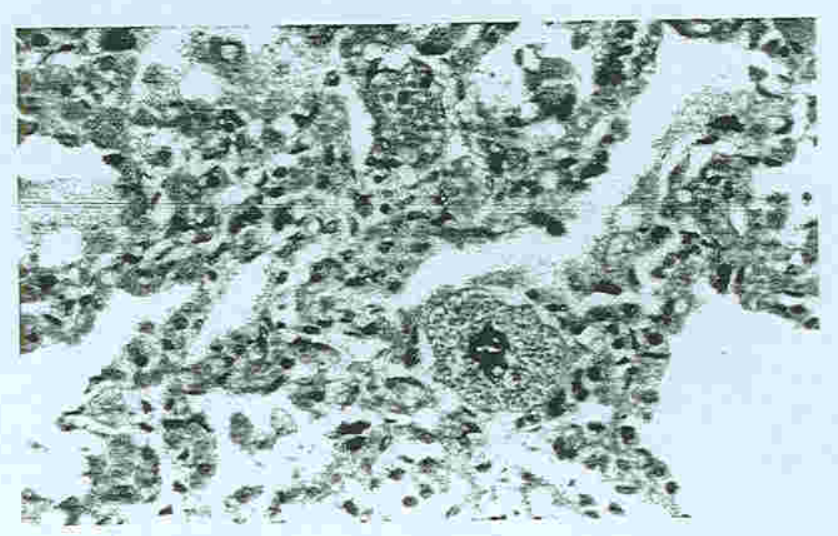

FIGURE 26. Congenital chagasic pneumonitis. See septal mononuclear infiltration and a parasitized giant cell within the alveolar lumen $(\mathrm{H} \& \mathrm{E}, \times 560)$. 
very low in the first three months of postnatal life when the level of fetal hemoglobin in high. Sporozoites introduced into the bloodstream mature in the liver and form the mature schizont that contains a great number of merozoites. After the release of merozoites the ring stage appears within erythrocytes in the peripheral blood with a subsequent transformation into tachyzoites. The sexual form is called gametocyte. In infections with $P$. vivax, $P$. malariae, and $P$. ovale all forms are seen in the blood but in infections with $P$. falciparum only rings and gametocytes are found [81].

It has been postulated that the placenta acts as a barrier to the plasmodium and that its blocking efficiency depends on the maternal immune status. The rate of congenital malaria in the immune mother is estimated to be $0.3 \%$ whereas in nonimmune mothers it is as high as $10 \%$ [82]. Although the parasite is rarely detected in the umbilical cord blood, the placenta shows parasitism and sometimes is so affected that it causes an effect on the fetus. Maternal malaria is an important cause of IUGR due to placental lesions as well as maternal anemia. The mean birthweight of the fetus is lower if the placenta is infected with P. falciparum [81].

Congenital infection occurs mainly in malaria caused by $P$. falciparum and $P$. vivax. The reported congenital cases presented in the first few months of life with splenomegaly and less frequently with hepatomegaly [81]. Evidence for malaria causing stillbirths is sparse. Asymptomatic congenital malaria with later disappearance of parasites may occur [80].

\section{SYPHILIS}

Treponema pallidum is a spirochete that measures $10-13 \mu \mathrm{m}$ in length and $0.2-$ $0.3 \mu \mathrm{m}$ in diameter. I. pallidum localizes preferentially in extracellular tissues, but it penetrates into the cells where it may persist causing a chronic and recidivant infection in nontreated individuals. The treponema is protected by a glycosamino glycan layer that impairs phagocytosis [83].

Although congenital transmission has been documented as early as 7 weeks of gestation, the fetal lesions appear only after the fourth month of gestation. Despite evidence for an immune response, syphilis progress and secondary lesions develop unless specific therapy is given. After 1 to 3 months of secondary lesions, spontaneous remission occurs and the patient enters a latency phase. Infection may become apparent only during childhood or adult life (tertiary syphilis). Pathologic changes in congenital syphilis are similar to those that occur in acquired syphilis [83]; however, the lesions may be more marked and extensive. Besides, lesions that occur only during the tertiary phase in the acquired syphilis, such as the gummatous lesions, may appear simultaneously with the secondary lesions [71].

Vessel changes are due to direct action of the treponemas and constitute an important event in the initiation of the host immune response to syphilitic infection. 
Membrane lipoproteins can activate the endothelial cells to upregulate the expression of intercellular adhesion molecule- 1 and procoagulant activity on its surface resulting in perivasculitis and fibrin deposition [83].

\section{Pathology}

The great majority of infected fetuses are macerated. Hydrops and hepatosplenomegaly are the most common macroscopic changes. In Brazil syphilis represents one of the most common causes of nonimmune hydrops [49]. The basilar meninges may appear thickened, especially around the brain stem and the chiasma optic [83].

In congenital syphilis besides macular, papular, and papulo-annular eruptions, an extensive vesicle-bullous lesion can be observed. In addition, a marked sloughing of the epidermis may be seen especially on the palms, soles, and around the mouth and anus. In cases of severe infection the lungs appear pale and heavy. For this reason the pulmonary lesions were formerly described as pneumonia alba. The pancreas may be increased in size and is firm due to fibrosis. The thymus is involuted and may present with abscesses of Dubois that constitute a pathognomonic aspect of congenital syphilis [71,84].

Whatever the stage of disease, the histologic hallmarks of congenital syphilis are obliterative endarteritis (luetic vasculitis), fibrosis, and macrophage-rich mononuclear infiltrates. Concentric fibrosis around the vessels appears as an onion-skin pattern that is very suggestive of congenital syphilis (Figure 27) [71, 84]. Abscesses of neutrophils also can be observed. Obliterative endarteritis and perivascular and interstitial fibrosis are characteristic. Less frequently, gummatous necrosis is observed [71]. Virtually every organ may be involved in congenital syphilis, but most frequently are the liver, kidney, bones, pancreas, spleen, eyes, bowel, skin and

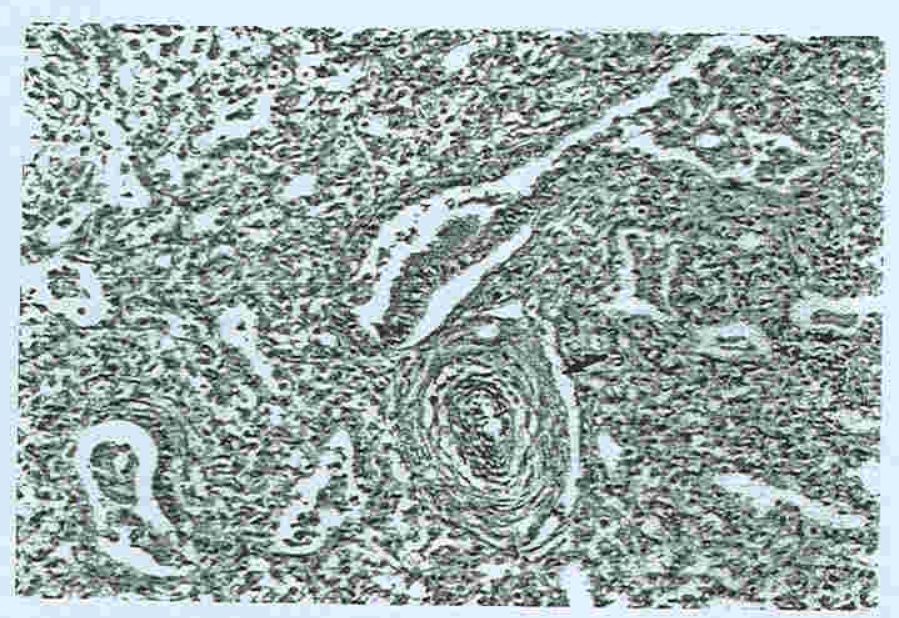

FIGURE 27. Pneumonia alba. There is septal thickening due to a marked proliferation of macrophages that are also seen inside the alveolar ducts. See concentric fibrosis (arrow) around a vessel (H\&E, $\times 200$ ). 
mucosae, testes and epididymus, hypophysis, lymph nodes, thymus, heart, lungs, and brain [84].

The lungs may be affected by a diffuse interstitial fibrosis and macrophage proliferation, sometimes accompanied by alveoli filled with macrophages (Figure 27). The pleura also exhibit a similar proliferation [71, 84]. The syphilitic thymus is represented by a lymphocyte depletion and fibrosis sometimes associated with neutrophil abscesses (Figure 28) [71].

There is always erythropoiesis in the liver. A mononuclear infiltrate is seen in the portal tracts, but it also can be intralobular. Less frequently, a diffuse hepatic fibrosis can be observed (Figure 29). Frequently an interstitial fibrosis is seen in the pancreas with atrophy of the parenchyma (Figure 30) [84].

The intestinal lesions occur in the small as well as in the large bowel. They may involve all the layers but are more severe in the mucosa and submucosa. In stillborn fetuses a severe atrophy of the glands with disappearance of the muscularis mucosae may occur (Figure 31). The more severe lesions are detected in intrauterine deaths (Table 3) [85]. A heavy intestinal inflammation may cause ulceration and stenosis in postnatal life [86].

In the kidneys besides hematopoiesis, interstitial fibrosis and mononuclear infiltration may be observed. These changes may lead to a tubular atrophy pattern similar to the collecting tubule hamartoma described in nonsyphilitic autopsy cases [87]. Membranous glomerulonephritis and more rarely proliferative glomerulonephritis have been described in congenital syphilis [71].

Hematopoiesis is sometimes associated with mononuclear infiltration in the spleen. The lymph nodes may present macrophage proliferation. In the testis are often marked inflammation and interstitial fibrosis [84].

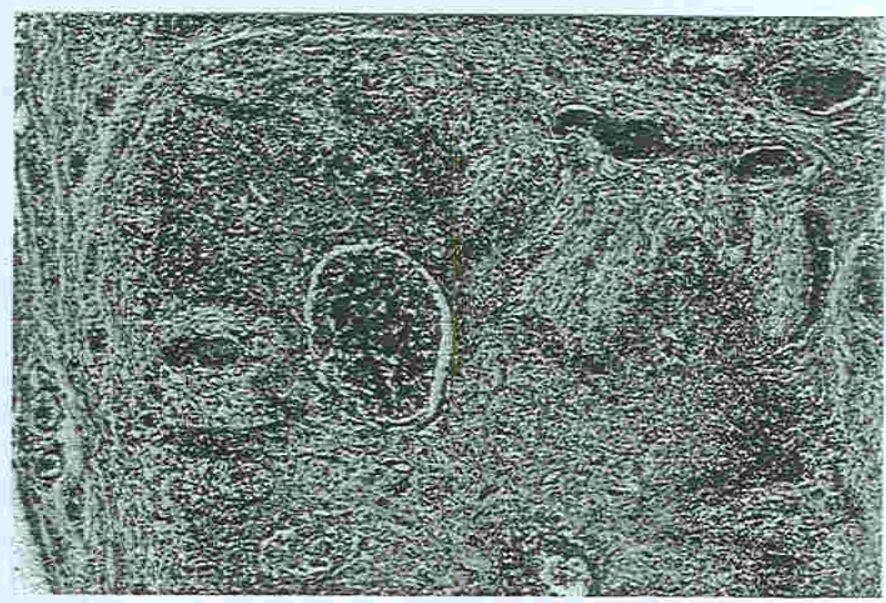

FIGURE 28. Thymus in congenital syphilis with a severe architectural desorganization. There is lymphocytic depletion, fibrosis, absence of Hassall corpuscles, and presence of Dubois abscess pathognomonic of congenital syphilis $(\mathrm{H} \& \mathrm{E}, \times 64)$. 


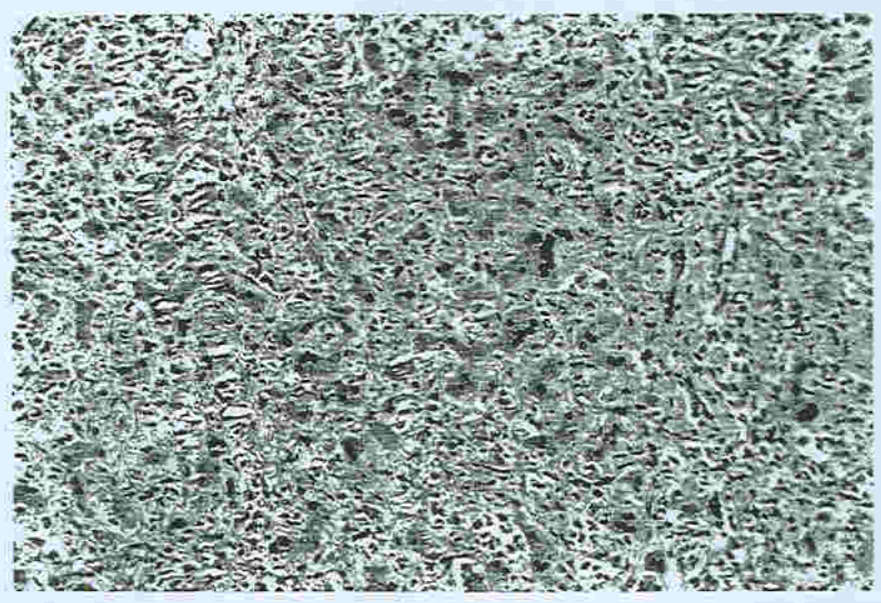

FIGURE 29. Congenital syphilis. Liver with intralobular fibrosis and mononuclear infiltration causing atrophy of the hepatocyte cords. Some of these hepatocyte resemble multinucleated giant cells ( $\mathrm{H} \& \mathrm{E}, \times 125)$ -

The CNS is frequently involved. Fully $86 \%$ of infants with clinical manifestations of syphilis present spirochetes in the cerebrospinal fluid. There is a frequent mononuclear infiltration in the leptomeninges. Microscopically endarteritis is commonly present and various degrees of neuronal injury may be observed. After resolution of infection fibrosis may ensue causing adhesions that obliterate the subarachnoid space leading in turn to an obstructive hydrocephalus or to cranial nerve palsies [83]. Chorioretinitis, glaucoma, uveitis, cataract, and chancre of the eyelid have been described $[83,84]$.

Syphilitic osteochondritis and periostitis may affect all bones, although lesions of the nose and lower legs are most distinctive. Destruction of the vomer

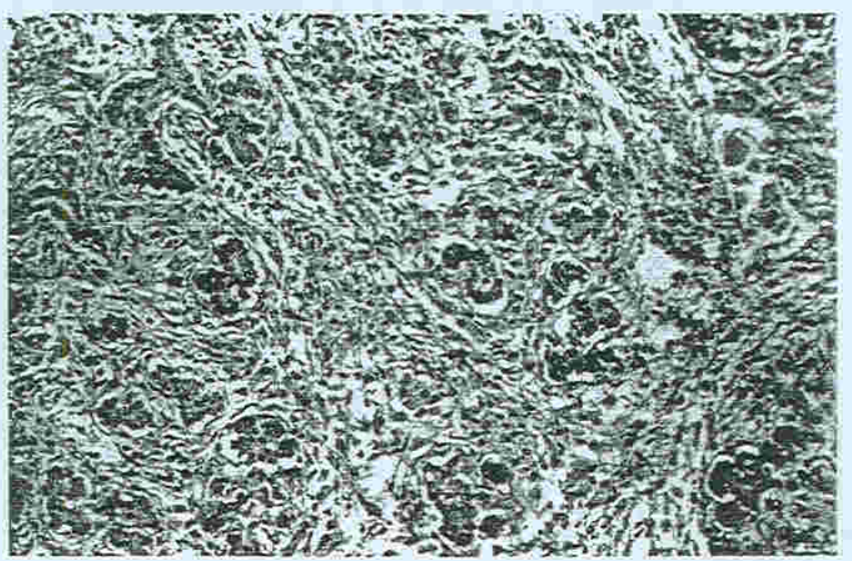

FIGURE 30. Congenital syphilis. Interstitial fibrosis in the pancreas isolating the acini (H\&E, $\times 125)$. 


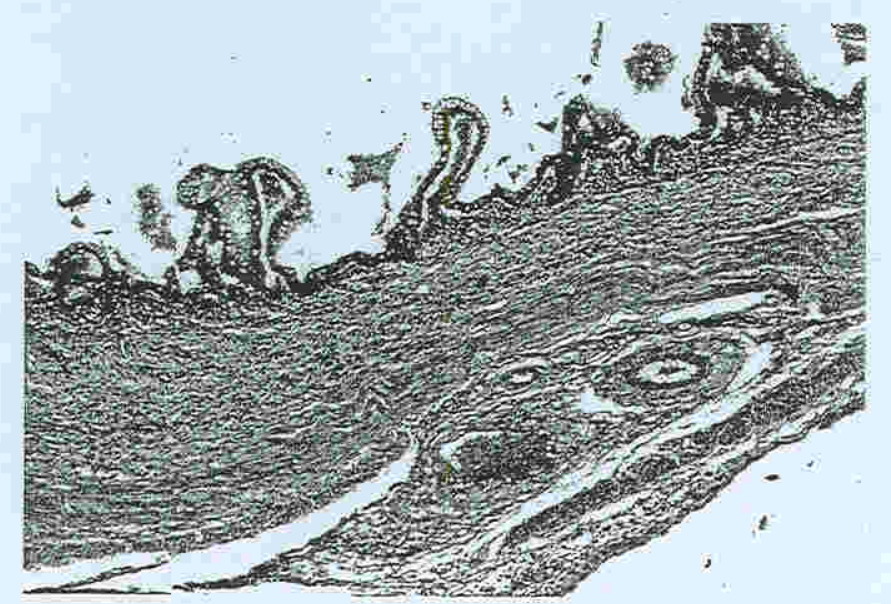

FIGURE 31. Congenital syphilis. Large beswet with a nurked atrophy of the mucosa, disappearamee of the

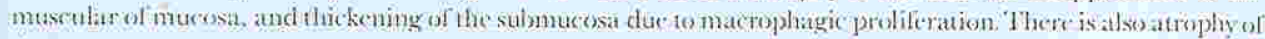
the external cont of the muscular layer $(\mathrm{H} \& \mathrm{E}, \times 64)$.

causes collapse of the bridge of the nose and, later on, the characteristic saddle nose deformity. Periostitis of the tibia leads to excessive bone growth on the anterior surface and anterior bowing (saber shin). Due to osteomyelitis, fractures may occur in long bones (Parrot pseudoparalysis). The epiphyses become widened as the cartilage overgrows, and cartilage is found as displaced islands within the metaphysis [83].

The macro- and microscopic lesions considered together constitute a characteristic pattern of congenital syphilis, as many of them are not observed in other congenital infections. However, the diagnosis of syphilitic infection may only be done through the identification of the spirochetes in the fetal organs, even in macerated fetuses (Figure 32) [71]. Through silver impregnation or immunohistochemistry the organisms may be demonstrated in many organs $[71,88]$. They also can be detected in fresh imprints of the organs and umbilical cord in dark field examination [71].

\section{LISTERIOSIS}

Listeria monocytogenes is a Gram-positive motile bacillus that may infect the fetus by the ascending route, hematogeneously, or by both routes.

Abortions, stillbirths, and IUGR generally occur in cases of early infection. The disease appears in two forms: first is the septicemic form with early onset, the second is meningoencephalitic with late onset. Neonatal infection of early onset is always congenital. When the clinical manifestations appear after the first $24 \mathrm{~h}$ of life (late-onset), it is only possible to determine the route of infection when the placenta is examined [89]. 


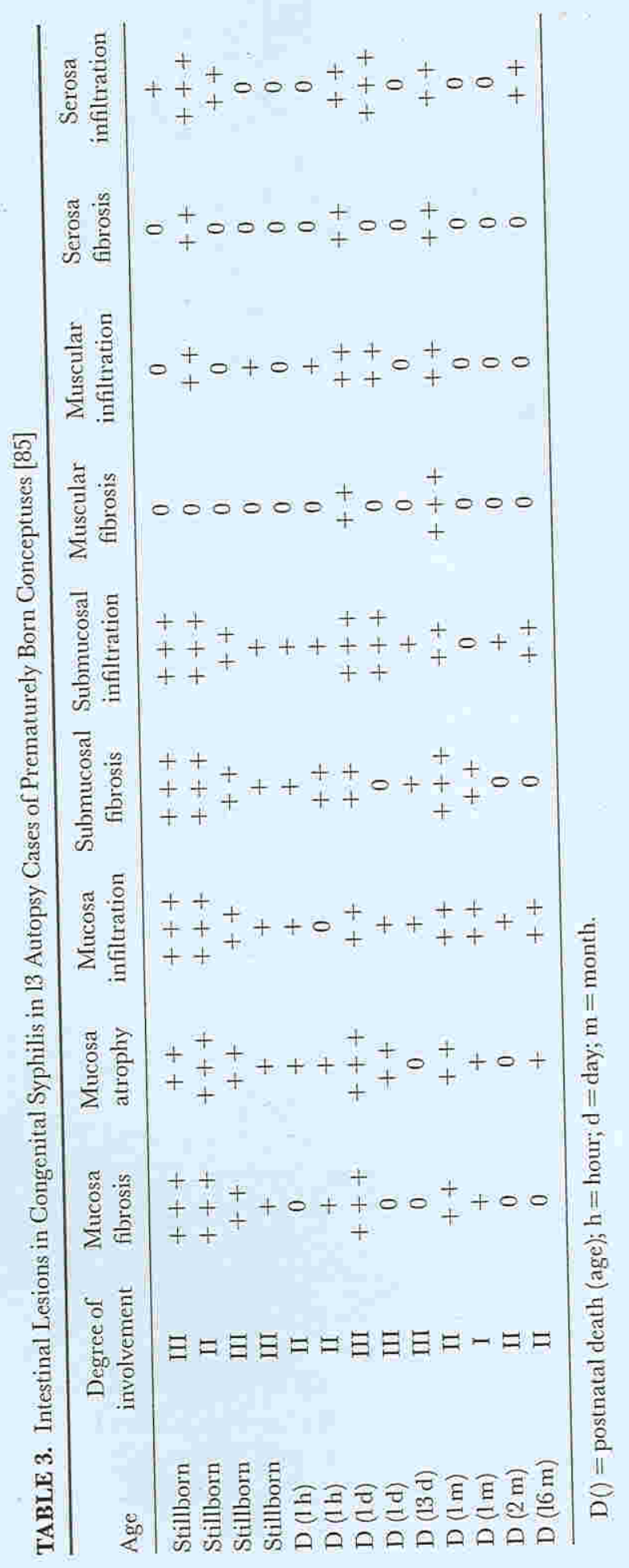




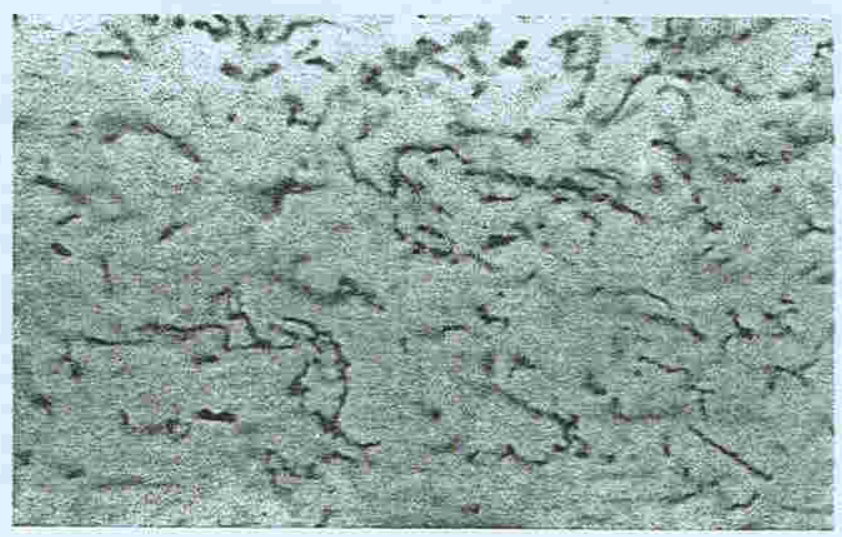

FIGURE 32. Congenital syphilis. Numerous treponemas present in a section of adrenal of a macerated fetus. (Levaditi, $\times 1250$ ).

In congenital infection there is always meconium staining of the amniotic fluid even in fetuses less than 32 weeks of life. The meconium staining before 32 weeks of gestation is very suggestive of listeriosis [89].

Listeria circulating in the blood are taken up by macrophages of the spleen, liver, lungs, and adrenals and most of the bacteria are killed. Listeria can also infect nonphagocytic cells, e.g., epithelial cells, hepatocytes, and fibroblasts, where the bacteria remain temporarily protected from the host defense [89]. Uptake by phagocytic cells is facilitated by opsonization with complement $\mathrm{C} 3 \mathrm{~b}$. The virulent organisms survive and multiply within the phagocytic vacuoles. However, listeria produces listeriolysin $\mathrm{O}$, a cytotoxin that destroys the bacteria-containing vacuole and enables the organism to escape to the cytosol. The release of $L$. monocytogenes to the cytosol leads to bacterial multiplication and actin polymerization. This last event is important in the cell-to-cell transfer of listeria avoiding any contact with the humoral mechanism of defense [90].

During the early phase of infection, Listeria-infected cells elicit a marked infiltration of neutrophils induced by chemotactic factors (bacterial components and complement) as well as pro-inflammatory cytokines (TNF- $\alpha$, IL-1, IL-6, and IL-8). This event is mediated by the activation of adhesion molecules. In this early preimmune phase, the invading phagocytes are able to lyse infected hepatocytes limitating infection. In addition, NK cells produce IFN- $\gamma$ that leads to I-cell-independent activation of monocytes and macrophages with increase in the expression of MHC class II [90].

However, host susceptibility to listeria infection depends mainly on the establishment of cell-mediated immunity. This explains why most cases of listeriosis affect immunodepressed hosts, frequently pregnant women, fetuses, and premature newborns. The susceptibility of the fetus and newborn to listeria may be related to the impairment of cell immunity that occurs at this phase of life. 


\section{Pathology}

Autopsies of the septicemic form of listeriosis show hepatosplenomegaly and widespread white-yellowish nodules in the liver, spleen, adrenals, lungs, esophagus, posterior pharyngeal wall, and tonsils. However, other organs may be involved. Hydrops also may occur. In severe infection a skin rash has been described with slightly elevated pale patches 1 to $2-\mathrm{mm}$ in diameter and surrounded by a red halo. In Figure 33, an abortus with widespread miliary necrotic lesions surrounded by a hemorhagic halo is shown. In the digestive and respiratory tracts the infection causes ulcerations due to mucosal necrotic lesions [90].

Microscopically the lesions consist of foci of necrosis (Figure 34) or microabscesses, sometimes surrounded by mononuclear cells and epithelioid cells. At necropsy, granulomas are not generally seen. However, in the individuals who survive the critical phase of infection, granulomas appear due to the development of a cellular immune response [89].

Late-onset listeriosis usually involves the CNS and manifests as meningitis, meningoencephalitis, or less frequently as rhomboencephalitis. The lesions may cause an occlusive hydrocephalus [90]. Less frequently, involvement of the CNS may occur in the early-onset listeriosis with extensive necrosis (Figure 35) and sometimes with the development of hydrocephalus [91].

The diagnosis of listeriosis is the bacterial isolation by culture of fetal lesions. However, when culture is not performed, the diagnosis can be made by maternal history, placental pathologic features, autopsy data, and identification of bacilli in tissues. Brown-Hopps stain demonstrates in the lesions Gram-positive pleomorphic rods (Figure 34), 0.4 to $0.5 \mu \mathrm{m}$ by 0.5 to $2.0 \mu \mathrm{m}$. The bacillius also can be revealed by Gomori methenamine-silver stain, Warthin-Starry, or other argentic methods.

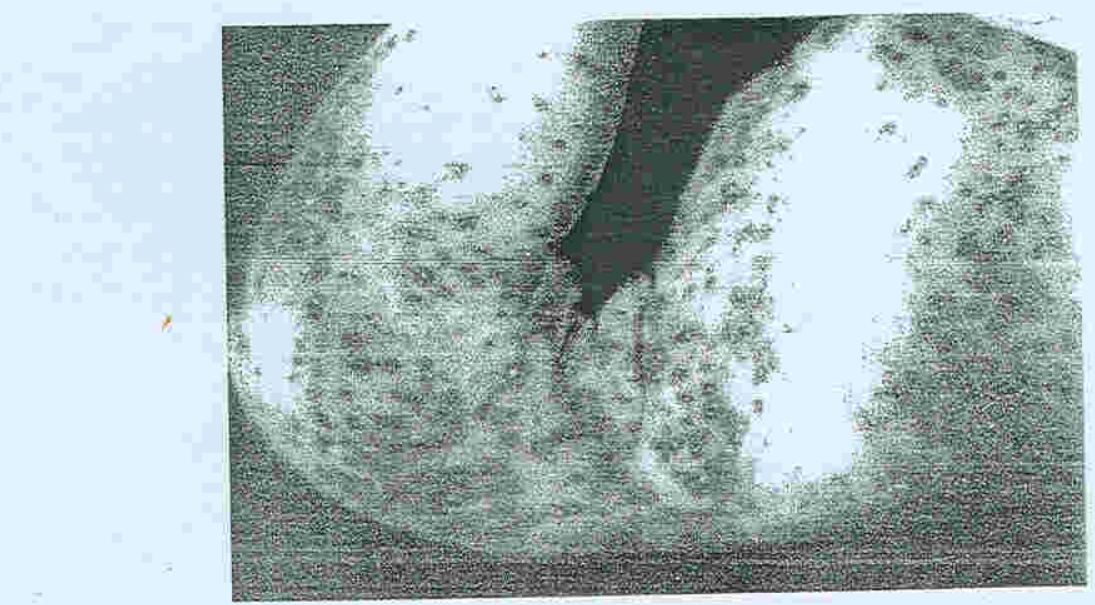

FIGURE 33. Abortus with hematogenous and ascending infection by L. monocytogenes. There are numerons and military necrotic cutaneous lesions with a hemorrhagic halo. 


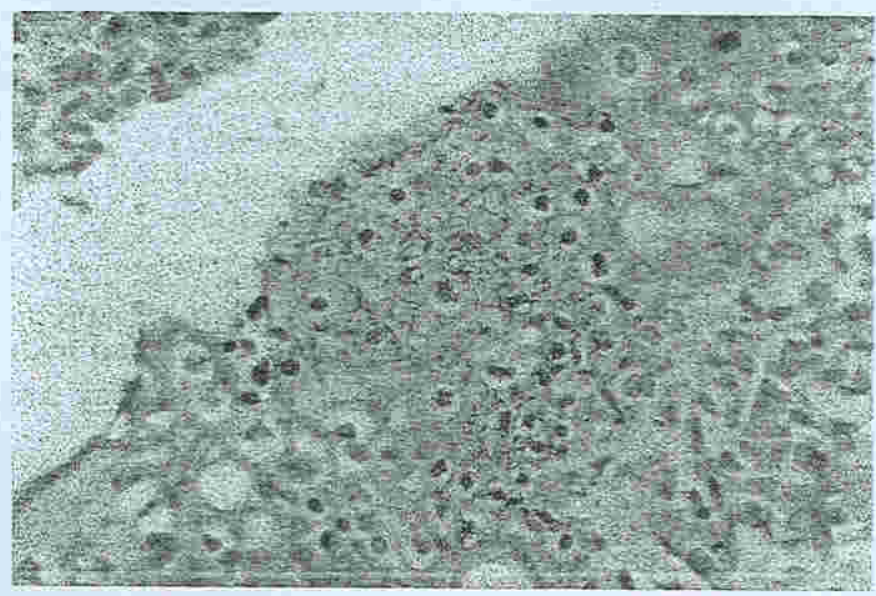

FIGURE 34. Congenital listeriosis. Microscopical aspect of lesion. See epidermal necrosis with numerous bacilli (Brown Hopps, x1250).

It is important to consider that the organisms may appear sometimes Gramnegative particularly in long-standing disease and when the patient has been treated with antibiotics [89]. To confirm the histopathologic diagnosis, immunohistochemistry and DNA hybridization can be used [90].

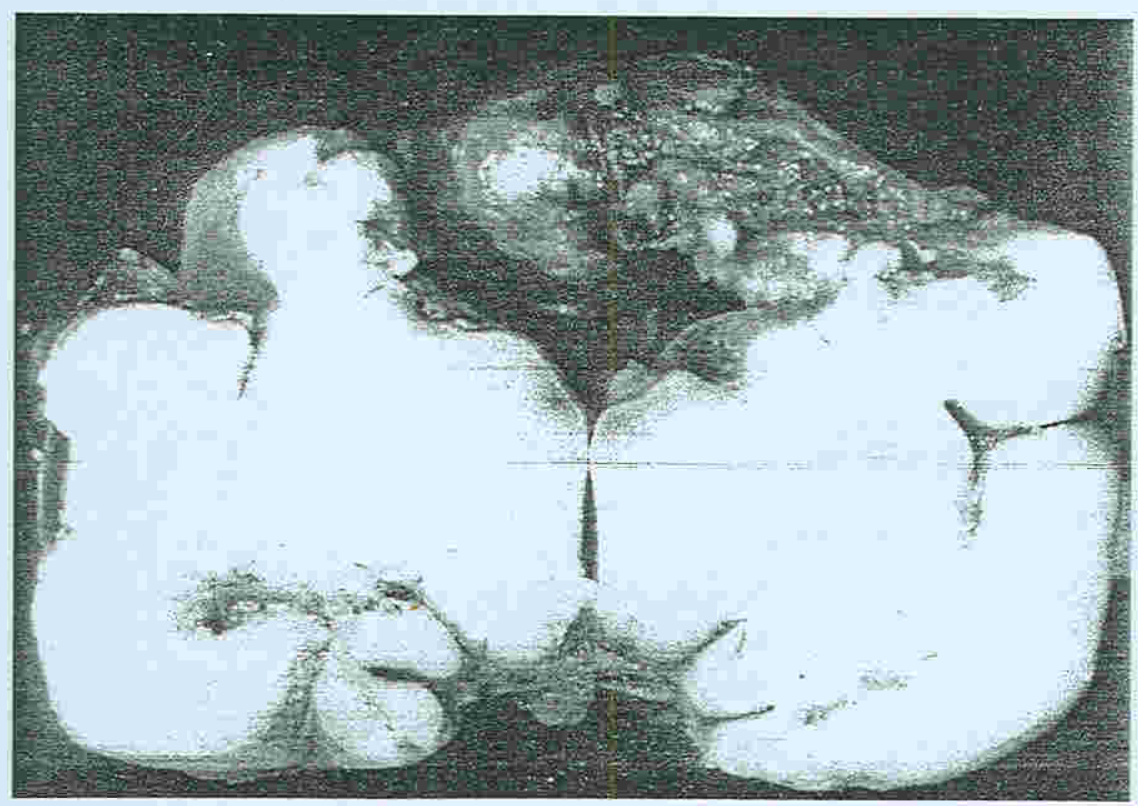

FIGURE 35. Early-onset listeriosis. Extensive destruction of the cerebral tissue. 


\section{RARE TRANSPLACENTAL CONGENITAL INFECTIONS}

\section{African Trypanosomiasis}

The majority of congenital cases of African trypanosomiasis are not well documented. Considering that the clinical manifestations of this infection generally are of late appearance, it is impossible in endemic areas to consider as congenital late manifestations of the disease [71]. Two cases of congenital disease have been observed in Europe, in infants born to infected mothers. One had hydrocephalus at birth and repeated convulsive episodes. The other was healthy until 18 months when the infant developed trypanosomal CNS infection [92].

\section{Visceral Leishmaniasis (Kala-Azar)}

Visceral leishmaniasis presents with a spectrum of clinicopathologic patterns varying from an asymptomatic form to a severe and generalized disease associated with an intense parasitism. Pregnant women with the generalized disease may infect the placenta and possibly the fetus [93]. There are few reports of probable congenital visceral leishmaniasis $[93,94]$. One presented IUGR and placental parasitism. At 7 months of age the infant developed hepatosplenomegaly and parasitism of the bone marrow and died a few days later. At autopsy parasitized macrophages were detected in many organs associated with interstitial pneumonitis [94].

\section{Borreliosis (Lyme Disease)}

Fetal infection has been described in Borrelia burgdorferi infection. Spirochetes have been found in brain, spleen, myocardium, and bone marrow, but inflammatory changes are much less than in adult cases and sometimes absent. In one case cardiac malformation was observed. The organisms can be demonstrated by argentic impregnation or by immunofluorescence using monoclonal antibodies [95].

\section{Campylobacter (Vibrio) Fetus Infection}

C. fetus, a common enteric pathogen in humans, has been described as the cause of prematurity, fetal death, and acute villitis [96,97]. It may cause meningitis and meningoencephalitis, and it has been isolated from fetal organs [96].

\section{Chlamydia Infection}

Congenital infection by $C$. trachomatis is considered to occur only by the ascending via. However, an abortus infected with C. trachomatis has been described showing pneumonitis and foci of hepatic necrosis. Chlamidial bodies identified by immunoflorescence using antichlamidial antibodies were observed in liver, brain, and eyes [98].

Placental C. psittaci infection is rarely recognized as a cause of acute placentitis; however, the histopathologic study of the fetuses is unremarkable in spite the fact that the agent was isolated from fetal heart blood and tissues [99]. 


\section{Q-Fever}

Q-fever is caused by Coxiella burnetii and has been incriminated as cause of abortion, prematurity, low birthweight, and fetal death. There is one well-documented case of congenital transmission of $C$. bumetii infection causing abortion. Inflammatory lesions were seen in the lungs, and the organism was detected in the placenta and fetal organs by immunofluorescence. In this case $C$. burnetti was isolated from the placenta and fetal kidney [100].

\section{Tuberculosis}

The fetus may be infected through the placenta or through the amniotic fluid that is primarily infected in the extraplacental membranes but not by an ascending route. The infection of the placenta may occur hematogeneously or by contiguity with tuberculous endometritis or salpingitis. There are only 30 cases of congenital tuberculosis reported in the literature [101].

After the placental infection, a primary complex is developed in the liver, the portal of entry of fetal infection, with involvement of the periportal lymph nodes. A later dissemination of infection may occur compromising many organs. When the infection is mediated by the amniotic fluid, the first involved areas are the lungs and gastrointestinal tract.

The infected conceptus presents hepatosplenomegaly, and papular or nodular cutaneous lesions can be observed [102]. The histopathologic diagnosis can be made by hepatic or cutaneous biopsy through the finding of a granulomatous reaction associated with caseous necrosis (Figure 36 ) and acid-fast bacilli.

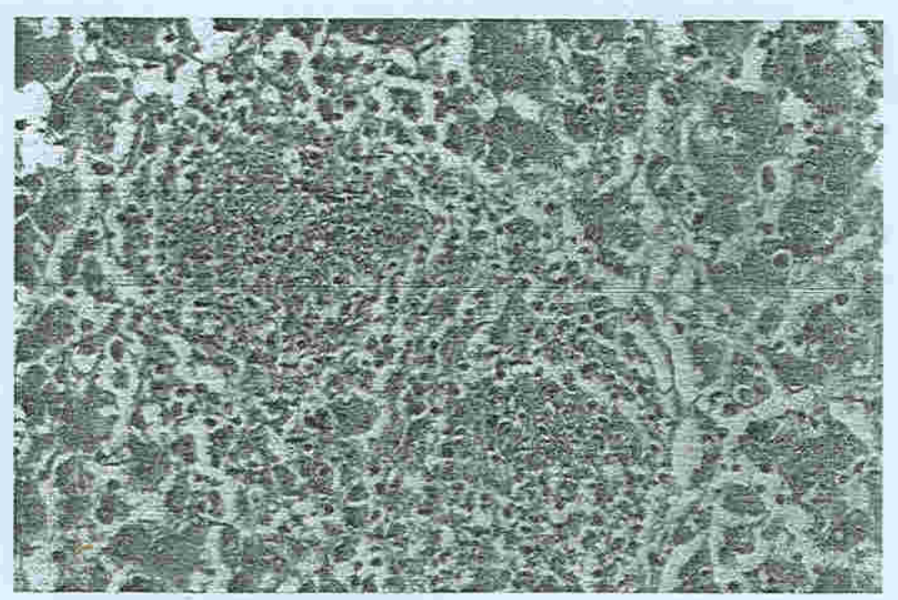

FIGURE 36. Liver in congenital tuberculosis. See two areas of caseous necrosis without granulomatous reaction. There is a mild infiltration of mononuclear cells around the necrotic areas ( $\mathrm{H} \& \mathrm{E}, \times 360)$. 


\section{Lymphocytic Choriomeningitis}

Congenital lymphocytic choriomeningitis is an infection rarely recognized as the cause of congenital infection. It may mimick congenital CMV infection and toxoplasmosis. Lymphocytic choriomeningitis causes ocular abnormalities, hydrocephalus, or microcephaly, intracranial calcifications, and chorioretinopathy [103].

\section{REFERENCES}

1. Knipe DM. Virus-host cell interactions. In Fields BN, Knipe DM, Howley PM, et al. Fields Virology. Philadelphia: Lippincott-Raven Publishers, 1996;273-300.

2. Tyler KL, Gonzalez-Scarano F. Viral diseases of the central nervous system. Acute infections. Nathanson, N. Viral Pathogenesis. Philadelphia: Lippincott-Raven Publishers, 1997;837-854.

3. Wolinsky JS, McCarthy M. In Porterfield JS. Exotic Viral Infections. New York: Chapman \& Hall Medical, 1995;19-45.

4. Cooper LZ, Preblud SR, Alford Jr. CA. Rubella. In RemingtonJS, KleinJO. Infectious Diseases of the Fetus \& Newborn. Philadelphia: WB Saunders, 1995; 268-311.

5. Singer DB. Infections of fetuses and neonates. In WigglesworthJS, Singer DB. Textbook of Fetal and Perinatal Pathology. Oxford: Blackwell Scientific Publ, 1991;525591.

6. Garcia AGP, Lana AMA. Embriopatia rubeólica. Estudo anátomo-histopatológico de 44 casos. J Ped (Brazil) 1975;40:137-148.

7. Esterly JR, Oppenheimer EH. Pathological lesions due to congenital rubella. Arch Pathol 1969;87:380-388.

8. Garcia AGP, Olinto F, Fortes T. Thymic hypoplasia due to congenital rubella. Arch Dis Childhood 1974;49:181-185.

9. Bosma TJ, Corbett KM, Eckstein MB, et al. Use of PCR for prenatal and postnatal diagnosis of congenital rubella. J Clin Microbiol 1995;33:2881-2887.

10. O'Neill JF. The ocular manifestations of congenital infection: a study of the early effect and long-term outcome of maternally transmitted rubella and toxoplasmosis. Trans Am Ophthalmol Soc 1998;96:813-879.

11. Stagno S. Cytomegalovirus. In RemingtonJS, Klein JO. Infectious Diseases of the Fetus \& Newborn. Philadelphia: WB Saunders, 1995; 312-345.

12. Lack EE, Chandler FW, Pearson GR. Cytomegalovirus infection. In Connor DH, Chandler FW, Schwartz DA, et al. Pathology of Infectious Diseases. Stamford: Appleton \& Lange, 1997; 91-99.

13. Kershisnik MM, Knisel YAS, Dun CC, et al. Cytomegalovirus infection, fetal liver disease, and neonatal hemochromatosis. Human Pathol 1992;23:1075-1080.

14. Stiskal J. Jacquette $M$, Kaplan $G$, et al. Congenital cytomegalovirus infection with gastrointestinal involvement. J Pediat 1997:13::168.

15. Chouquet C, Burgard M, Richardson S, et al. Timing of mother-to-child HIV-1 transmission and diagnosis of infection based on polymerase chain reaction in the neonatal period by a non-parametric method. AIDS 1997;11:1183-1199. 
16. Mayaux MJ, Teglas JP, Mandelbrot L, et al. Acceptability and impact of zidovudine for prevention of mother-to-child human immunodeficiency virus-1 transmission in France. J. Pediatr 1997:131:857-862.

17. Greco MA, Zagzag D. Human immunodeficiency virus infection lesion in the pediatric age group. In Cannor DH, Chandler FW, Schwartz DA, et al. Pathology of Infectious Disease. Stamford: Appleton \& Lange, 1997;169-181.

18. Tovo PA, Martino M, Gabiano C, et al. Prognostic factors and survival in children with perinatal HIV-1 infection. Lancet 1992:339:1249-1253.

19. Zanetti AR, Tanzi E, Paccagnini S, et al. Mother-to-infant transmission of hepatitis C virus. Lancet 1995;345:289-291.

20. Schulte JM, Burkham S, Hamaker D, et al. Syphilis among HIV-infected mothers and their infants in Texas from 1988 to 1994. SexTransm Dis 2001;28:315-320.

21. Lozano JS, AmadorJT, Bodas A, et al. Prevalence of congenital CMV in children born to HIV-infected women. In 12th World AIDS Conference, Geneve, Switzerland, 1998.

22. Pillay T, Adhikari M, MokiliJ, et al. Severe, rapidly progressive human immunodeficiency virus type 1 disease in newborns with co-infections. Pediatr Infect Dis J 2001;20:404-410.

23. Schwebke K, Henry K, BalfourJr HH, et al. Congenital cytomegalovirus infection as a result of nonprimary cytomegalovirus disease in a mother with acquired immunodeficiency syndrome. J Pediatr 1995;126:293-294.

24. Pegado CS, Garcia AGP, Basso NG, et al. Congenital toxoplasmosis in a neonate of HIV infected mother. Ann Diagn Pediatr Pathol 1997;1:267-270.

25. Alter MJ, Gallagher M, Morris TT, et al. Acute non-A-E hepatitis in the United States and the role of hepatitis $G$ virus infection. Sentinel countries virus hepatitis study team. N EnglJ Med 1997;336:741-746.

26. Lachaux A, Lapillonne A, Bouvier $R$, et al. Transplacental transmission of hepatitis $B$ virus: a familial case. Pediatr Infect Dis J 1995:14:60-63.

27. Sharma $R$, Malik A, Rattan A, et al. Hepatitis $B$ virus infection in pregnant women and its transmission to infants. J Trop Pediatr 1996;42:352-354.

28. Agha S, Sherif LS, Allan MA, et al. Transplacental transmission of hepatitis C virus in HIV-negative mothers. Res Virol 1998:149:229-234.

29. Leikin E, Lysikiewicz A, Garry D, et al. Intrauterine transmission of hepatitis A virus. Obstet Gynecol 1996;88:690-691.

30. Feucht H, Zöllner B, Polywka S, et al. Vertical transmission of hepatitis G. Lancet 1996;347:615.

31. Khuroo MS, Kamili S, Jameel S. Vertical transmission of hepatitis E virus. Lancet 1995:345:1025-1026.

32. Schweitzer IL, Dunn AEG, Peters RL, et al. Viral hepatitis B in neonates and infants. AmJ Med 1973;55:762-771.

33. Kushnir VN, Slepova OS, Zaitseva NS, et al. Viral hepatitis B as a factor in the etiology of cataracts in adults and children. Vestn-Oftalmol 1996:112:46-50.

34. Zeldis JB, Crumpacker CS. Hepatitis. In RemingtonJS, Klein JO. Infectious Disease of the Fetus \& Newborn. Philadelphia: WB Saunders, 1995; 805-829.

35. Scheuer PJ. Viral hepatitis. In MacSween RNM, Anthony PP, Scheuer PJ, et al. Pathology of the Liver. London: Churchill Livingstone, 1994; 243-268. 
36. Yeung LTF, King SM, Roberts EA. Mother-to-infant transmission of hepatitis C virus. Hepatology 2001;34:223-229.

37. Ketzinel-Gilad M, Colodner SL, Hadary R, et al. Transient transmission of hepatitis C virus from mothers to newborns. Eur J Clin Microbiol Infect Dis 2000;19: $267-274$.

38. Wejstal R, Manson AS, Widell A, et al. Perinatal trasmission of hepatitis G virus (GB virus type $C$ ) and hepatitis C virus infections - a comparison. Clin Infect Dis 1999;28:816-821.

39. Schroter $B$, Chaoui $R$, Meisel H, et al. Maternal hepatitis B infection as the cause of nonimmunologic hydrops fetalis. Z Geburtshilfe Neonatol 1999;203:36-38.

40. Arvin AM. Viral infections of the fetus and neonate. In Nathanson N, Almed R, Gonzalez-Scarano F, et al. Viral Pathogenesis. New York: Lippincott-Raven, 1996; 801-814.

41. Gershon AA. Chickenpox, measles and mumps. In Remington JS, Klein JO. Infectious Diseases of the Fetus \& Newborn. Philadelphia: WB Saunders, 1995; 565-603.

42. Magliocco AM, Demetrick DJ, Sarnat HB, et al. Varicella embryopathy. Arch Pathol Lab Med 1992;116:181-186.

43. Scharf A, Scherr O, Enders G, et al. Virus detection in the fetal tissue of a premature delivery with a congenital varicella syndrome. A case report. J Perinat Med 1990;18:317-323.

44. Garcia AGP. Fetal infection in chickenpox and alastrim with histopathological study of the placenta. Pediatrics 1963:32:895-901.

45. Dimova PS, Karparov AA. Congenital varicella syndrome: case with isolated brain damage. J Child Neurol 2001;16:595-597.

46. Whitley RJ, Arvin AM. Herpes simplex virus infections. In Remington JS, Klein JO. Infectious Diseases of the Fetus \& Newborn. Philadelphia: WB Saunders, 1995; 354-372.

47. Nakanura Y, Yamamoto $S$, Tanaka $S$, et al. Herpes simplex viral infection in human neonates: an immunohistochemical and electron microscopic study. Hum Pathol 16:1091-1097.

48. Nicoll JAR. Use of the polymerase chain reaction to detect herpes simplex virus DNA in paraffin sections of human brain at necropsy. $J$ Neurol Neurosurg Psych 1991:54:167-168.

49. Garcia AGP, Pegado SC, Ramos HIB, et al. Non-immunologic hydrops fetalis: study of 86 autopsies. Trop Doctor 1996;78-79.

50. Török TJ. Human parvorirus B 19. In RemingtonJS, KleinJ. Infectious Diseases of the Fetus \& Newborn. Philadelphia: WB Saunders, 1995; 668-693.

51. Brown KE, Hibbs JR, Gallinella G, et al. Resistance to parvovirus B19 infection due to lack of virus receptor (erythrocyte P antigen). N EnglJ Med 1994;330:11921196.

52. Public Health Laboratory Service Working Party on Fifth Disease. Prospective study of human parvovirus (B19) infection in pregnancy. $\mathrm{Br}$ Med J 1990;300: 1166-1170.

53. Morey AL, Keeling JW, Porter HJ, et al. Clinical and histopathological features of parvovirus B19 infection in the humans fetus. BrJ Obstet Gynecol 1992;99:566-574. 
54. Garcia AGP, Pegado CS, Cubel RCN, et al. Feto placentary pathology in human parvovirus B19 infection. Rev Inst Med Trop S Paulo 1998;40:145 150.

55. Hartwig NG, Vermeij-Keess (i, Van Elsacker-Nicle $\Lambda M W$, et al. Embryonic malformations in a ease of intraterine parvovirus Bl9 infection. Teratology $1989 ; 39: 295 \quad 302$.

56. Weiland H'T, Vermey-Keers CHR, Salimans MMM, et al. Parvovirus B19 associated with fetal abnormality. Lancet 1987;682 6883.

57. Jordan JA. Identification of human parvovirus B19 infection in idiopathic nonimmune hydrops fetalis. $\Lambda \mathrm{m}$ J Obstet Gynecol 1996;174:37-42.

58. Cubd RCN, Garcia AGP, Pegado CS, et al. Human parvovirus B19 infection and hydrops fetalis in Rio de Janciro, Brazil. Mem Inst Oswaldo Cruz 1996;91:147 151.

59. Cherry.J1. Enteroviruses. In Remington.JS, Klein.JO. Infectious Diseases of the Fetus \& Newborm. Philadelphia: WB Saunders, 1995; 404438.

60. Basso NG, Fonseca ME, Garcia A, et al. Enterovirus isolation from foetal and placental tissues. Acta Virol 1990;34:49-57.

61. Bates HR. Coxsackic virus B13 calcificd pancarditis and hydrops fetalis. Am J Obstet Gynecol 1970:106:629-630.

62. Batcup G, Holt P, Hambling MH, et al. Placental and fetal pathology in Coxsackic virus A9 infection: a case report. Histopathology 1985;9:1227-1235.

63. Baker DA, Philips CA. Maternal and neonatal infection with Coxsackie virus. Obstet Gynecol 1980;55:12S-15S.

64. Gareia AGP, Basso NGS, Fonseca MET, et al. Congenital ECHO virus infectionmorphological and virological study of fctal and placental tissue. J Pathol 1990:160:123-127.

65. Bose CL, Gooch III M, Sanders GO, et al. Dissimilar manifestations of intrauterine infection with echovirus 11 in premature twins. Arch Pathol Lab Med 1983;107: $36 \mathrm{l}-363$.

66. Jones MJ, Kolb M, Votava HJ, et al. Intrauterine echovirus type 11 infection. Mayo Clin Proc 1980:55:509-512.

67. Cheeseman SH, Kirsch MS, Keller EW, et al. Fatal neonatal pneumonia caused by echovirus type 9. Am J Dis Child 1977;131:1169.

68. Toce SS, Kecman WJ. Congenital echovirus 11 pneumonia in association with pulmonary hypertension. Pediat Infect Dis.J 1988;7:360-361.

69. Remington JS, McLeod R, Desmonts G. Toxoplasmosis. In Remington JS, Klein JO. Infectious Diseases of the Fetus \& Newborn. Philadelphia: WB Saunders, 1995; 140-26\%.

70. Altshuler G. Toxoplasmosis as a cause of hydranencephaly. Am J Dis Child 1973:125:251-252.

71. Bittencourt AL, Garcia AGP. Patogenia e patologia. In Bittencourt AL. Infecções Congênitas Hematogênicas. Rio de Janeiro: Revinter, 1995; 39-79.

72. Roberts F, Mets MB, Ferguson DJ, et al. Histopathological features of ocular toxoplasmosis in the fetus and infant. Arch Ophthalmol 2001;119:51-58.

73. Garcia AGP, Torres AC, Pegado CS. Congenital toxoplasmic myocarditis: case report of an unusual presentation. Ann Trop Ped 1985;5:227-230. 
74. Lucas SB. Other viral and infectious diseases and HIV-related liver disease. In MacSween RNM, Anthony PP, Scheuer PJ, et al. Pathology of the Liver. London: Churchill Livingstonc, 1994; 269315.

75. JohnsonJD, Butcher PD, Savva D, et al. Application of the polymerase chain reaction to the diagnosis of human toxoplasmosis. J Infect 1993;26:147-158.

76. Bittencourt AL, Ashworth T. American trypanosomiasis (Chagas' disease). In Doerr W, Seifert G. Tropical Pathology. Berlin: Springer Verlag, 1995; 653-704.

77. Bittencourt AL, Vieira GO, Tavares HC, et al. Esophageal involvement in congenital Chagas' disease. Report of a case with megaesophagus. AmJ Trop Med Hyg 1984:33:30-33.

78. Bittencourt AL. American trypanosomiasis. In MacLeod CL. Parasitic Infections in Pregnancy and the Newborn. Oxford: Oxford Med Publ 1988; 62-86.

79. Bittencourt AL. Congenital Chagas' disease. A review. Am J Dis Child 1976;130:97103.

80. MacLeod CL. Malária. In MacLeod CL. Parasitic Infections in Pregnancy and the Newborn. Oxford: Oxford Med Publ 1988; 8-42.

81. Arvin AM, Maldonado YA. Protozoan and helmintic infections (including Pneumocystis carinii). In Remington JS, Klein JO. Infectious Diseases of the Fetus \& Newborn. Philadelphia: WB Saunders, 1995; 757-769.

82. Quinn TC, Jacobs RF, Mertz GJ, et al. Congenital malaria: a report of four cases and a review. J Pediatr 1982;101:229-232.

83. Ingall D, Sánchez PJ, Musher D. Syphilis. In Remington JS, Klein JO. Infectious Diseases of the Fetus \& Newborn. Philadelphia: WB Saunders, 1995; 529-557.

84. Oppenheimer EH, Hardy JB. Congenital syphilis in the newborn infant: clinical and pathological observations in recent cases. John Hopkins Med J 1971;129:63-82.

85. Bittencourt AL, Freitas LAR. As lesões intestinais da sifilis congênita. Acta Med Port 1979;1:569-575.

86. Ajayi NA, Marven S, Kaschula RO, et al. Intestinal ulceration, obstruction, and haemorrhage in congenital syphilis. Pediatr Surg Int 1999;15:391-393.

87. Finegold MJ. Collecting tubule hamartoma. Another form of renal dysplasia. Arch Path 1970;90:31-34.

88. Guarner J, Greer P, Bartlett J, et al. Congenital syphilis in a newborn: an immunopathologic study. Mod Pathol 1999;12:88-87.

89. Bortolussi R, Schlech WF. Listeriosis. In Remington JS, Klein JO. Infectious Diseases of the Fetus \& Newborn. Philadelphia: WB Saunders, 1995; 1055-1068.

90. Mielke MEA, Held TK, Unger M. Listeriosis. In Connor DH, Chandler FW, Schwartz DA, et al. Pathology of Infectious Diseases. Stamford: Appleton \& Lange, $1977 ; 621-633$.

91. Paolillo F, Ercoli AM, Belloni C, et al. Listeriosi perinatale. Descrizione di un caso con esito in idrocefalo. Minerva Pediatr 1991;43:601-603.

92. Reinhardt MC, McLeod CL. African trypanosomiasis (African sleeping sickness). In MacLeod CL. Parasitic Infections in Pregnancy and the Newborn. Oxford: Oxford Med Publ 1988; 43-61.

93. Eltoum IA, Zulstra EE, Ali M, et al. Congenital Kala-azar and leishmaniasis in the placenta. AmJ Trop Med Hyg 1992;46:57-62. 
94. Nyakundi PM, Muigai R, Were JBO, et al. Congenital visceral leishmaniasis: case report. Trans Roy Soc Trop Med Hyg 1988;82:564.

95. Duray PH, Chandler FW. Lyme disease. In Connor DH, et al. Pathology of Infectious Disease. Stamford: Appleton \& Lange, 1997; 635-646.

96. Eden AN. Perinatal mortality caused by Vibrio fetus. J Pediatr 1966;68:297-304.

97. Gribble MJ, Salit IE, Isaac-Renton J, et al. Campylobacter infections in pregnancy. Am J Obstet Gynecol 1981;140:423-426.

98. Garcia AGP, Leite MEL, Fonseca MEF, et al. Infeç̧ão materna por Chlamidia trachomatis associada a aborto fetal. J Bras Ginecol 1994;104:383-386.

99. Wong SY, Gray ES, Buxton D, et al. Acute placentitis and spontaneous abortion caused by Chlamydia pittaci of sheep origin: a histological and ultrastructural study. J Clin Pathol 1985;38:707-711.

100. Raoult D, Stein A. Q-fever during pregnancy - a risk for women, fetuses, and obstetricians. N EnglJ Med 1994:330-371.

101. Pham Duy L, LeVan N, Truong HNC. Congenital miliary tuberculosis. A propos of a case. Rev Pneumol Clin 1998;54:207-209.

102. Smith MH, Teele DW. Tuberculosis. In RemingtonJS, KleinJO. Infectious Diseases of the Fetus \& Newborn. Philadelphia: WB Saunders, 1995; 1074-1084.

103. Wrigth R, Johnson D, Neumann M, et al. Congenital lymphocytic choriomeningitis virus syndrome: a disease that mimics congenital toxoplasmosis or cytomegalovirus infection. Pediatrics 1997;100:E9. 